\title{
DISH: DEMOCRACY IN STATE HOUSES
}

\author{
A Thesis \\ presented to \\ the Faculty of California Polytechnic State University, \\ San Luis Obispo \\ In Partial Fulfillment \\ of the Requirements for the Degree \\ Master of Science in Computer Science
}

by

Nicholas Russo

February 2019 
(c) 2019

Nicholas Russo

ALL RIGHTS RESERVED 


\section{COMMITTEE MEMBERSHIP}

TITLE:

AUTHOR:

DATE SUBMITTED: $\quad$ February 2019

COMmitTeE CHAIR: Alexander Dekhtyar, Ph.D.

Professor of Computer Science

COMMITTEE MEMBER: Foaad Khosmood, Ph.D.

Professor of Computer Science

COMMITTEE MEMBER: Franz Kurfess, Ph.D.

Professor of Computer Science 


\section{ABSTRACT \\ DiSH: Democracy in State Houses}

Nicholas Russo

In our current political climate, state level legislators have become increasingly important. Due to cuts in funding and growing focus at the national level, public oversight for these legislators has drastically decreased. This makes it difficult for citizens and activists to understand the relationships and commonalities between legislators. This thesis provides three contributions to address this issue. First, we created a data set containing over 1200 features focused on a legislator's activity on bills. Second, we created embeddings that represented a legislator's level of activity and engagement for a given bill using a custom model called Democracy2Vec. Third, we provided a case study focused on the 2015-2016 California State Legislator and had our results verified by a political expert. Our results show that our embeddings can explain relationships between legislator and how they will likely act during the legislative process. 


\section{ACKNOWLEDGMENTS}

Thanks to:

- My family, for their unwavering love and support throughout this process.

- Bailey Blair, for constantly supporting me and pushing me to be my best.

- My advisor, Alex Dekhtyar, for shaping my career through his indispensable advice and guidance.

- My committee members, Foaad Khosmood and Franz Kurfess, for their feedback and assistance throughout this unusual process.

- Daniel Kauffman, for letting me use his bill topic modeling system.

- Alex Boyd, for convincing me to use PyTorch and dealing with the consequences. 


\section{TABLE OF CONTENTS}

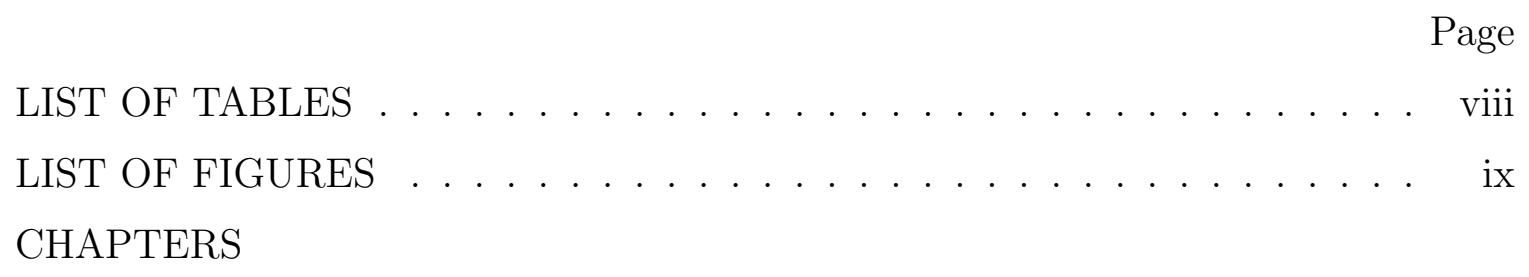

1 Introduction . . . . . . . . . . . . . . . . . 1

1.1 Motivation .......................... 1

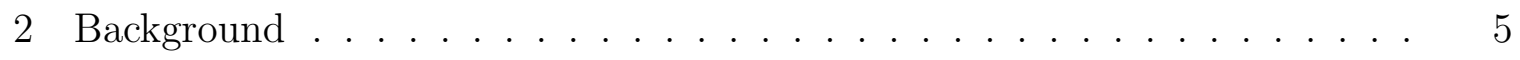

2.1 California State Legislative Process . . . . . . . . . . . 5

2.2 Digital Democracy . . . . . . . . . . . . . 6

2.3 Neural Networks . . . . . . . . . . . . . . . . . . . . . 8

2.4 Word2Vec . . . . . . . . . . . . . . . . . 11

2.5 Principal Component Analysis . . . . . . . . . . . . . . 13

2.6 Latent Dirichlet Allocation . . . . . . . . . . . . . . . . 13

2.7 Software Packages . . . . . . . . . . . . . . . . . 14

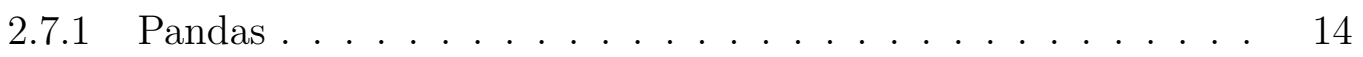

2.7.2 TextBlob .................................. 14

2.7.3 Vader Sentiment . . . . . . . . . . . . . . . 14

3 Related Work . . . . . . . . . . . . . . . . . . . . . 15

4 The Legislator's Activity on Bills (LAB) Dataset . . . . . . . . . . . . 18

4.1 The Digital Democracy Project Database Overview . . . . . . . . . . 18

4.2 Extraction Methods . . . . . . . . . . . . . . . 18

4.3 Legislator Features . . . . . . . . . . . . . . . . . . . . . 19

4.4 Bill Features . . . . . . . . . . . . . . . 22

4.5 Activity Features . . . . . . . . . . . . . . 26

5 Democracy2Vec . . . . . . . . . . . . . . . . . . . . . . 29

5.1 Data Filtering . . . . . . . . . . . . . . 29

5.1.1 Voting Percentage................ 29

5.1 .2 Unique Voters . . . . . . . . . . . . . . . . . 30

5.1.3 Feature Reduction ................ . . 30 
5.2 Network Motivation . . . . . . . . . . . . . . . . . . . . . 31

5.3 Single Embedding Section . . . . . . . . . . . . . . . . . . 33

5.4 Multiple Embedding Section . . . . . . . . . . . . . . . . . . 34

5.5 Output Section . . . . . . . . . . . . . . . . . 34

5.6 Explanation . . . . . . . . . . . . . . . . . 35

6 Experiments . . . . . . . . . . . . . . . . . . . 37

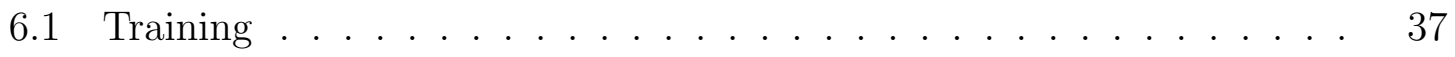

6.2 Embeddings . . . . . . . . . . . . . . . . . . . . . . 38

7 Case Study . . . . . . . . . . . . . . . . . . . . . . . . . . . . 40

7.1 Validation Method . . . . . . . . . . . . . . . . . 40

7.1.1 Important Senate Democrats Cluster (Cluster 5) . . . . . . . 40

7.1.2 Important Senate Republicans Cluster (Cluster 4) . . . . . . . 42

7.1.3 Centered Senators Cluster (Cluster 0) . . . . . . . . . . . . 43

7.1.4 Centered Assemblymen Cluster (Cluster 1) . . . . . . . . . 44

7.1.5 Education-Focused Cluster (Cluster 3) . . . . . . . . . 46

7.1.6 Democratic Line Breakers Cluster (Cluster 2) . . . . . . . 48

7.1.7 Republicans Line Breaker Cluster (Cluster 7) . . . . . . . 49

7.1.8 Partisan Legislator Cluster (Cluster 6) . . . . . . . . 50

7.1 .9 Misclassifications . . . . . . . . . . . . . . . . . 51

8 Conclusion and Future Work . . . . . . . . . . . . . . . . . . . 53

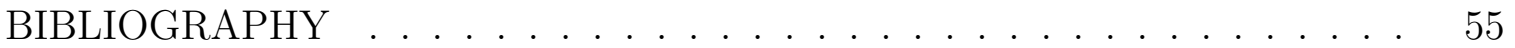




\section{LIST OF TABLES}

Table

4.1 Legislator Features . . . . . . . . . . . . . . . 22

4.2 Bill Features . . . . . . . . . . . . . 26

$4.3 \quad$ Participation Features . . . . . . . . . . . . . . . 28

$5.1 \quad$ Final Feature Set . . . . . . . . . . . . . . . 31

5.2 Output Features . . . . . . . . . . . . . . . 35

6.1 Loss Weight used in Training. . . . . . . . . . . . . . . 38

6.2 Sponsorship precision, recall, and F-score on our training data set. . 38

6.3 Sponsorship precision, recall, and F-score on our test data set. . . . 38

7.1 Cluster 5 legislators. . . . . . . . . . . . . . 41

7.2 Cluster 4 legislators. . . . . . . . . . . . . . . . . 42

7.3 Cluster 0 legislators. . . . . . . . . . . . . . . . 44

7.4 Cluster 1 legislators. . . . . . . . . . . . . . 45

7.5 Cluster 3 legislators. . . . . . . . . . . . . . 47

7.6 Cluster 2 legislators. . . . . . . . . . . . . . . 49

7.7 Cluster 7 legislators. . . . . . . . . . . . . . . . 50

$7.8 \quad$ Cluster 7 legislators. . . . . . . . . . . . . . . 51 


\section{LIST OF FIGURES}

Figure

1.1 The Digital Democracy project's legislator web page. . . . . . . . 2

1.2 The Digital Democracy project's voting data. . . . . . . . . . 3

2.1 California bill life cycle $[2] \ldots \ldots \ldots \ldots$

2.2 Digital Democracy committee hearing with transcription. . . . . . . 7

2.3 Digital Democracy committee hearing with transcription. . . . . . . 9

2.4 A single neuron. . . . . . . . . . . . . . . . . 10

2.5 Skip-Gram model. . . . . . . . . . . . . . . . . . . . . . 11

$2.6 \quad$ CBOW model. . . . . . . . . . . . . . . . . . . . . 12

2.7 Example of PCA reducing 3 dimensions to 2 dimension. . . . . . . 13

5.1 Democracy2Vec model, amount of neurons and weights not to scale. 33

6.1 Average embeddings colored by house. . . . . . . . . . . . . . . 39

6.2 Average embeddings colored by party. . . . . . . . . . . . . . 39

6.3 Embeddings averaged over all bills, colored by K-Means clusters. . . 39

7.1 Important Senate Democrats Cluster . . . . . . . . . . . . . 40

7.2 Important Senate Republicans Cluster . . . . . . . . . . . . . . 42

7.3 Centered Senators Cluster . . . . . . . . . . . . . . 43

7.4 Centered Assemblymen Cluster . . . . . . . . . . . . . . 44

7.5 Education-Focused Cluster . . . . . . . . . . . 46

7.6 Democratic Line Breakers . . . . . . . . . . . . . . . . . . 48

7.7 Republicans Line Breaker Cluster . . . . . . . . . . . . . . . . . 49

7.8 Partisan Legislators Cluster . . . . . . . . . . . . . . . . 50 


\section{Chapter 1}

\section{INTRODUCTION}

\subsection{Motivation}

In our current political climate, the importance of state-level legislatures has grown tremendously. As the federal government continues to turn more partisan, there is a gridlock between the two opposing parties. This makes pushing any piece of legislation to completion difficult, all the while, state legislatures have gone in the opposite direction. In 2019, 49 of the 50 states will be controlled by one party[7]. This allows state legislators to be more bold in the type of legislation they present, especially in states whose legislature is comfortably controlled by one party. As a result, state legislation serves as trial runs and test cases for federal-level legislators hoping to propose similar legislation. Although these state legislatures have grown to be even more important, the level of public oversight and coverage has decreased dramatically[15][6][8]. Large media companies have become hyper focused on the national level of politics, drawing the public's attention away from the level of government that more directly affects them. With the public drawn in, it is more economically appropriate for companies to shift their funding and coverage away from the state legislators. This trickles down to local media stations who can not afford to fund full-time positions meant to cover state-level affairs. Without these staff members, it has become increasingly difficult to stay up-to-date with the state legislatures.

Legally, the state legislatures must provide the public with information about legislators, committees, and their hearings. However, this information is hard to obtain, and, is in formats that are difficult to investigate. For example, in California,

the state legislature provides videos of the committee hearings, but the transcriptions 
of committee hearings were not required until recently. Even for an active and engaged citizen, there are hundreds of bills with multiple hearings and versions. It is difficult and time consuming to go through days worth of video on one bill, just to find a small segment of a committee hearing they are interested in. Without local reporters, there is no one to summarize the hearings, drastically decreasing the legislature's transparency, and ultimately dampening the public's ability to influence the legislative process. By making it difficult for citizens to get involved, the legislative process has evolved into a negotiation between legislators and special interest groups. These special interest groups can make selfish stances on bills without fear of public backlash.

To address this issue, the Digital Democracy project was created ${ }^{1}$. Digital Democracy provides a fully indexed and searchable database filled with information about California, New York, Florida, and Texas state legislatures. This information includes fully transcribed and searchable hearing videos, the position of organizations on bills, donations to legislators, voting records, and more.

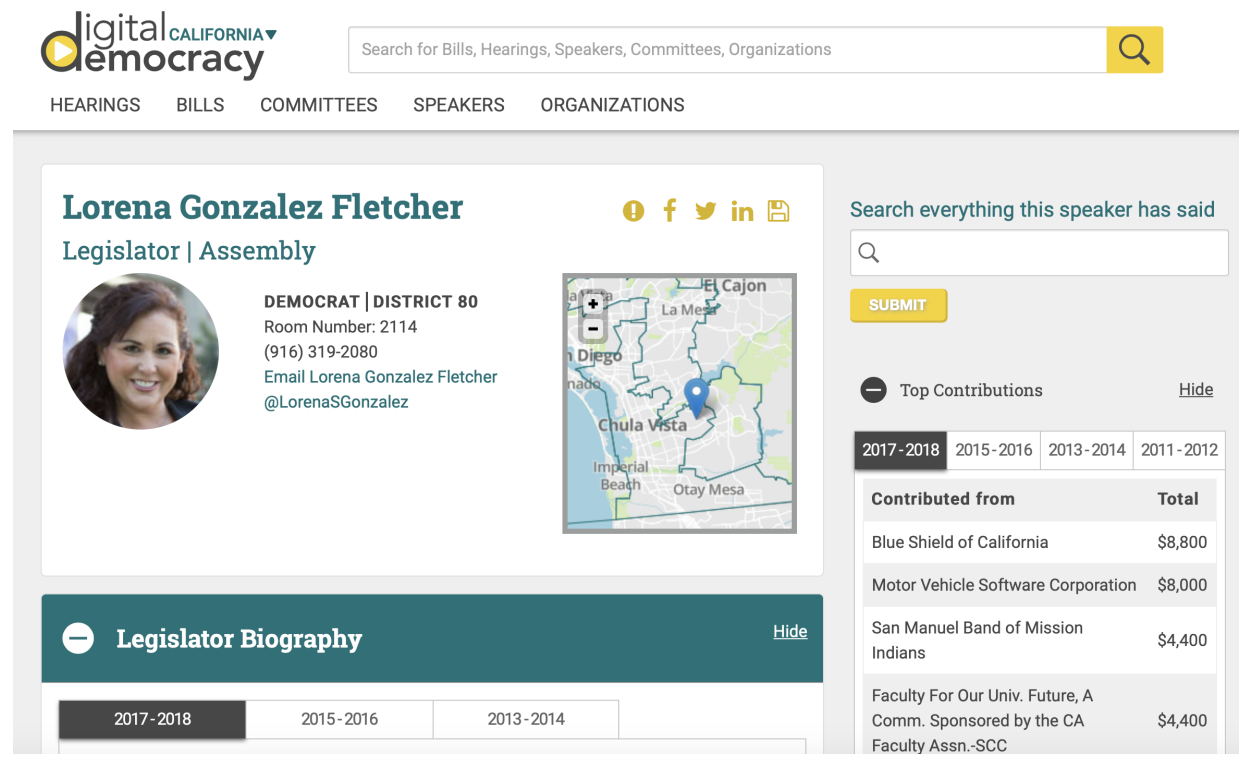

Figure 1.1: The Digital Democracy project's legislator web page.

\footnotetext{
${ }^{1}$ www.digitaldemocracy.org
} 


\section{AUGUST 31, 2016 I SENATE STANDING COMMITTEE ON BUSINESS, PROFESSIONS AND ECONOMIC DEVELOPMENT}

That the Assembly amendments be concurred in

Ayes: 9 Noes: 0 Abstain: 0

Aye Votes

Bates, P. Gaines, T. Hernandez, E. Jackson, H. Wieckowski,

Block, M. Galgiani, C. Hill, J. Mendoza, T. B.

\begin{tabular}{|c|c|c|c|c|c|}
\hline \multicolumn{6}{|c|}{ Ayes: 38 Noes: 0 Abstain: 1} \\
\hline \multicolumn{6}{|c|}{ Abstain/Absent Votes } \\
\hline \multicolumn{6}{|l|}{$\begin{array}{l}\text { Moorlach, J. } \\
\text { Aye Votes }\end{array}$} \\
\hline $\begin{array}{l}\text { Allen, B. } \\
\text { Anderson, J. } \\
\text { Bates, P. } \\
\text { Beall, J. } \\
\text { Berryhill, T. } \\
\text { Block, M. } \\
\text { Cannella, A. }\end{array}$ & $\begin{array}{l}\text { De Leon, K. } \\
\text { Fuller, J. } \\
\text { Gaines, T. } \\
\text { Galgiani, C. } \\
\text { Glazer, S. } \\
\text { Hall, I. } \\
\text { Hancock, L. }\end{array}$ & $\begin{array}{l}\text { Hernandez, E. } \\
\text { Hertzberg, R. } \\
\text { Hill, J. } \\
\text { Hueso, B. } \\
\text { Huff, B. } \\
\text { Jackson, H. } \\
\text { Lara, R. }\end{array}$ & $\begin{array}{l}\text { Leno, M. } \\
\text { Leyva, C. } \\
\text { Liu, C. } \\
\text { McGuire, M. } \\
\text { Mendoza, T. } \\
\text { Mitchell, H. } \\
\text { Monning, B. }\end{array}$ & $\begin{array}{l}\text { Morrell, M. } \\
\text { Nguyen, J. } \\
\text { Nielsen, J. } \\
\text { Pan, R. } \\
\text { Pavley, F. } \\
\text { Roth, R. } \\
\text { Stone, J. }\end{array}$ & $\begin{array}{l}\text { Vidak, A. } \\
\text { Wieckowski, } \\
\text { B. } \\
\text { Wolk, L. }\end{array}$ \\
\hline
\end{tabular}

\section{Figure 1.2: The Digital Democracy project's voting data.}

While Digital Democracy provides a plethora of resources to track and monitor state level legislatures, it is still difficult to predict how active and involved a legislator will be during a given bill's life cycle. By solely looking at key artifacts, such as the legislator's final vote, it is still difficult to determine how active a legislator was during the bills life cycle. Our goal is to analyze data from the 2015-2016 California State Legislature so that we can summarize and quantify a legislator's activity across all bills.

Formally, this thesis provides a novel method for summarizing a legislature's level of activity for a given bill. This summary is represented by an embedding created from a custom neural network called Democracy2Vec. After performing a case study on the 2015-2016 California State Legislature, we were able to validate that our legislators were clustering into 8 distinct groups. These groups can summarize how 
legislators will likely act over a session and on a specific bill. Going forward, these embeddings can be used for further research similarly to how word embeddings are used.

This thesis provides the following contributions. First, we created a dataset with over 1200 features related to a legislator's activity on bills. This dataset was created for the 2015-2016 and 2017-2018 California State Legislature session, the 20172018 Florida State Legislature session, and the 2015-2016 New York State Legislature session. These datasets have been provided to the Digital Democracy Research platform. Second, we created a novel neural network called Democracy2Vec and were able to extract embeddings related to legislator activity. These embeddings will also be provided to the Digital Democracy Research platform for further research. Third, we conducted a case study which verifies that the embeddings are meaningful and accurately represent the legislators.

The rest of this document is structured as follows. In Chapters 2 and 3, we go over background information and related work including information about neural networks, embeddings, and research using the Digital Democracy database. Chapter 4 discusses how we extracted data from the Digital Democracy database and how we engineered over 1200 new features. After this we explain our custom neural network, Democracy2Vec, in Chapter 5. Specifically, we discuss how we filtered our data and the structure of the Democracy2Vec model. Next, in Chapter 6, we discuss a case study conducted using the data created from the 2015-2016 California State Legislature. Chapter 7 describes the results of our case study. Finally, Chapter 8 goes over future work. 
Chapter 2

BACKGROUND

\subsection{California State Legislative Process}

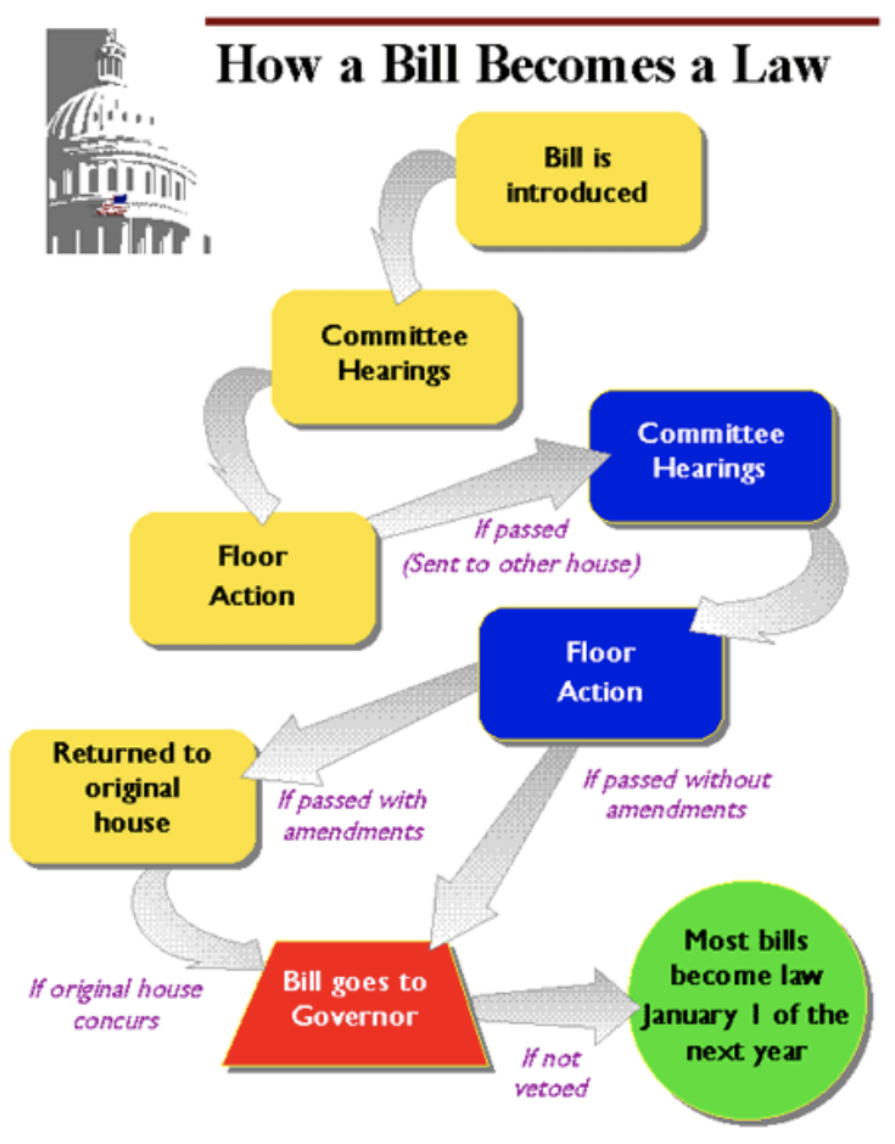

Figure 2.1: California bill life cycle [2].

The California state legislature is broken down into two chambers, the Senate and Assembly. Both of these chambers introduce hundreds of bills each year. The legislative process is both a long and complex system that is increasingly opaque. This is especially evident during a bill's life cycle. When a legislator has an idea for a bill, the legislator sends the bill to the legislative counsel to be drafted. After the bill is drafted, the bill is introduced to either the Senate or Assembly, depending on the chamber of the author and can not be acted upon for 30 days after it has been 
introduced. Once the bill has been introduced, it is sent to the Rules Committee in the author's chamber; the Rules Committee then sends the bill to committees that delegate over related policy, funding, or ethics. Each committee schedules a hearing to discuss and vote on the bill. Members can vote to pass the bill, pass an amended version of the bill, or defeat the bill by a majority vote. If the bill was passed, it is read for a second time to the floor committee of the authors chamber and assigned a third reading. For the third reading, the author explains the bill and members of the floor perform a roll call vote to pass or defeat the bill. If the bill is defeated, the author can appeal the vote for reconsideration. If the bill passes, the entire process is repeated in the opposite chamber. If the bill passes in the opposite chamber but is amended, the bills differences are resolved with a joint conference committee hearing if the amendments are not initially accepted by the original chamber. If both chambers pass the bill, the bill is sent to the Governor where they can either sign the bill into law or veto it. If the bill is vetoed by the Governor, both houses can overrule it with a two-thirds majority vote.[12]

\section{$2.2 \quad$ Digital Democracy}

As evident in Figure 2.1, the legislative process for creating new legislation is fairly elaborate. During this process, most of a legislator's activity happens during committee hearings. These committee hearings not only have legislators but many citizen and lobbyists speaking for or against a bill. All of these hearings are legally required to be filmed and thus provide a public record of a legislator's stance and passion on a bill. While these videos are publicly available, the state legislature has made it difficult to find and view these videos. Citizens, reporters, or lobbyists would have to comb through hundreds of hours of video to find a specific hearing and section where the legislator of interest is speaking on the desired bill. This problem is exacerbated by recent cuts to funding for full time state legislature reports. As international news 
corporations focus more on the drama and gridlock of the national government, the public has had less interest in the state legislatures. Because of this, the local media stations can not afford to have full time state legislature reporters. Without these reporters, there is no one to summarize what is happening in state governments. To counter this, the Digital Democracy project was started in 2015 by the Institute of Advanced Technology and Public Policy at the California Polytechnic State University, San Luis Obispo.

Digital Democracy aims to make the state legislatures of California, New York, Texas, and Florida more transparent[3]. To do this, Digital Democracy aggregates hundreds of gigabytes of data related to these legislatures. For California, all committee hearing videos during a session year are downloaded and upscaled through a transcription process. This transcription process involves adding captions to each of the videos while labeling who is speaking and on what bill.

\section{Assembly Budget Subcommittee No. 1 on Health and Human Services Hearing of 05-16- 2018}

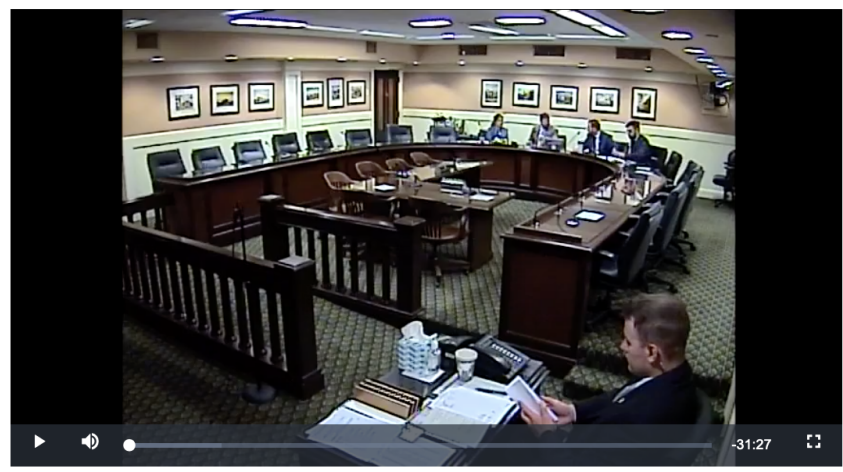

Transcript

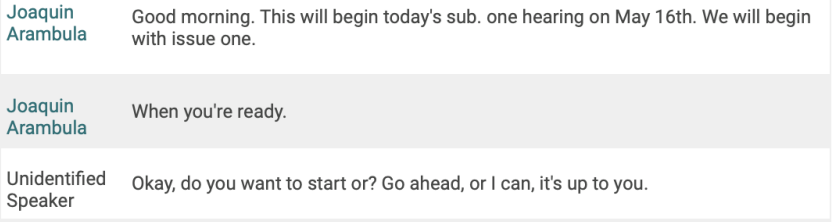

\begin{tabular}{ll}
\hline SEARCH HEARING STATEMENTS \\
\hline Agendized Bills & \\
\hline Hearing Speakers & \\
\hline Abouhassan, Evelyn & \\
Ader, Mary & Jordean, Barry \\
Allen, Chaz & Keeslar, Karen \\
Alonzo-Diaz, Lupe & Kent, Jennifer \\
Arambula, Joaquin & Kniffen, Susanna \\
Backus, Glen & Mandsey, Jordan \\
Bargmann, Nancy & Mark, Karen \\
Beckley, Mark & Mecca, Frank \\
Bellow, Jenny & Millendez, Ryan \\
Brooks, Sarah & Morales, Monica \\
Brooks, Kelly & Morales, Lourdes \\
Carvacha, Rosanna & Mossberg, Kathy \\
Cervenka, Peter & Mossburg, Kathleen \\
Cervinka, Pete & Mossburg, Kathy \\
Chen, Kimberly & Nguy, Linda \\
Chernenko, Pete & Obernolte, Jay \\
Child, Curt & Petek, Sonja \\
Child, Curtis L. & Peterson, Jonathan \\
Child, Kurt & Pettick, Sonia \\
Clendenin, Stephanie & Pittman, Brianna \\
Cook, Chris & Pryor, Selena \\
Cook, Kris & Rollins, Rick \\
Dougherty, Brian & Rubio, Blanca \\
Doyle, John & Schwartz, Angie \\
Ewing, Toby & Secretary, Committee \\
Freitas-Norman, & Sever, Will \\
Lindsey & Shane, Andrew \\
Gaffney, Leslie & Shilton, Adrienne \\
& \\
\hline
\end{tabular}

Figure 2.2: Digital Democracy committee hearing with transcription. 
Additionally, Digital Democracy collects more traditional data on legislators and bills. For a legislator, the project collects the legislator's party, chamber, district, committee membership, voting activity on each bill, and more. For each bill, the Digital Democracy collects data such as who the author is, who sponsors the bill and the changes to the bill content.. A full list of this data can be found in the appendix. All of this data is available for free to the public in a searchable database. This make Digital Democracy an indispensable tool for journalists reporting on the state governments and activists pushing for change at the state level.

\section{$2.3 \quad$ Neural Networks}

In this thesis, we use neural networks to classify data. Given a set of inputs and output classes, a neural network can learn a functional relationships between these sets of variables and predict which class the inputs belongs to. For example, given medical measurements of a tumor, a neural network could predict whether the tumor was benign or malignant. When trained, a neural network can learn the function between the inputs and expected output or class.

When broken down, a neural network has unique three components: neurons, weights, and layers. Neurons represent a series of transformation operations and are usually depicted as circles. The weights are paths or connections between neurons represented by a value and an arrow. Finally, layers are groups of neurons, depicted as a line of neurons or circles. A neural network has different types of layers: one input layer, one to many hidden layer(s), and one output layer. These layers are connected through matrices of weights that are randomly initialized. An example of a neural network can be seen in Figure 2.3. 


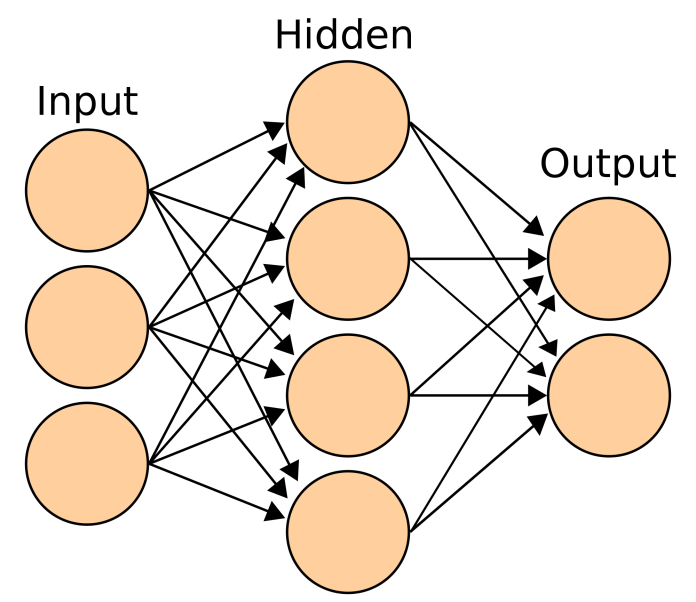

Figure 2.3: Digital Democracy committee hearing with transcription.

The layers are comprised of several neurons. The neurons in the input layer represent the input features for the given data set and no operations are performed. For each neuron in the hidden layer, the following series of transformation operations occur.

$$
Y_{i}=\varphi\left(\sum X_{i} W_{i}\right)
$$

For each neuron, the output values of the previous layer are multiplied by their weights, summed, then passed through a function $\varphi$ called an activation function. 


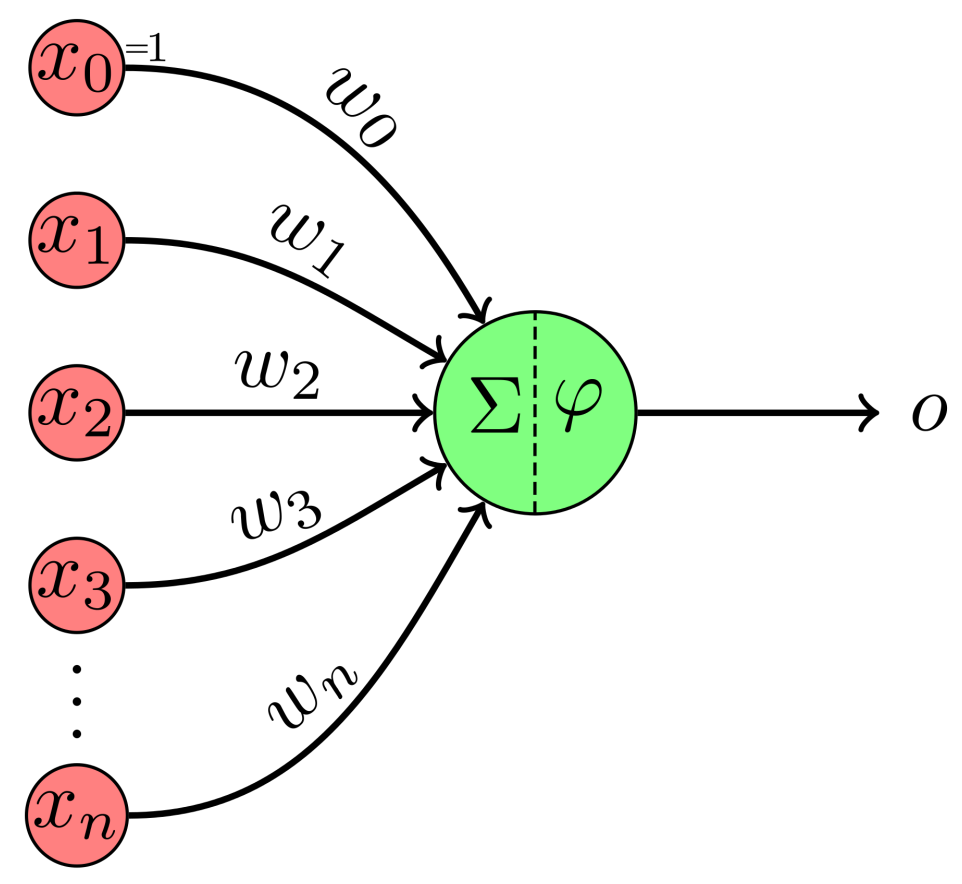

Figure 2.4: A single neuron.

The activation functions limit the output of a neuron to a specific range depending on the function. An example is the sigmoid formula which limits output from 0 to 1. These operations are performed for each neuron in a hidden layer and then repeated for each hidden layer. Generally, each neuron in the hidden layer(s) are connected to every neuron in the next layer. In Figure 2.4, we show what occurs at the neuron level. For the output layer, the same operations are performed, but the activation function is optional.

For a neural network to learn non-obvious relationships, it must be trained with a lot of data. Training is broken down into two steps: forward propagation and backward propagation. For forward propagation, inputs $X_{1}$ to $X_{n}$ are passed through each hidden layer and an output is calculated. Once an ouput is computed, back propagation starts by calculating a loss between the output and a ground truth. The loss is used to adjust weights throughout the network. This is done by taking the partial derivatives with respect to the weights using the chain rule. By adjusting 
the weights, the network is learning about the importance of each feature and can get a value closer to the ground truth.

\subsection{Word2Vec}

Our custom neural network architecture was inspired by Google's Word2Vec. In this paper, Mikolov et al.[28] created two shallow neural network architectures: Skip-Gram and Continuous Bag of Words (CBOW). The goal of a Skip-Gram model is given a single word, predict the two words before the input word and two words after.

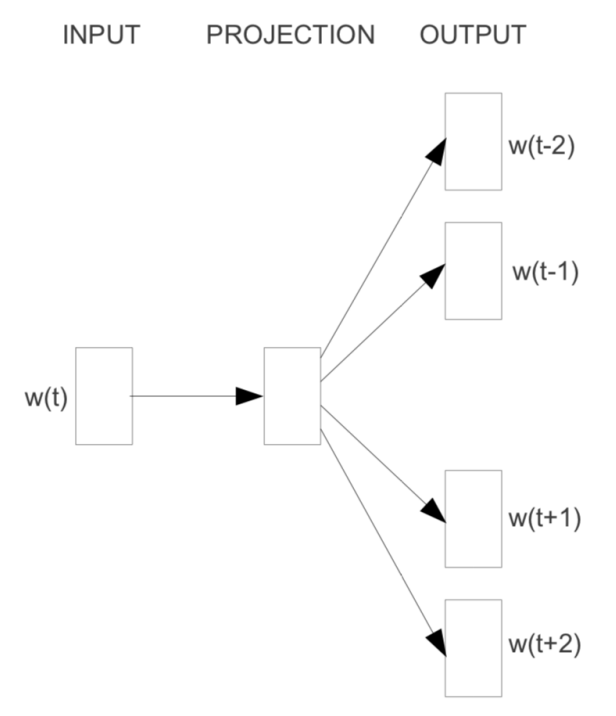

Skip-gram

Figure 2.5: Skip-Gram model.

The goal of a Continuous Bag of Words model is to predict a word given the context in a sentence. The context for a CBOW model is the two words prior the target word and two words after. 


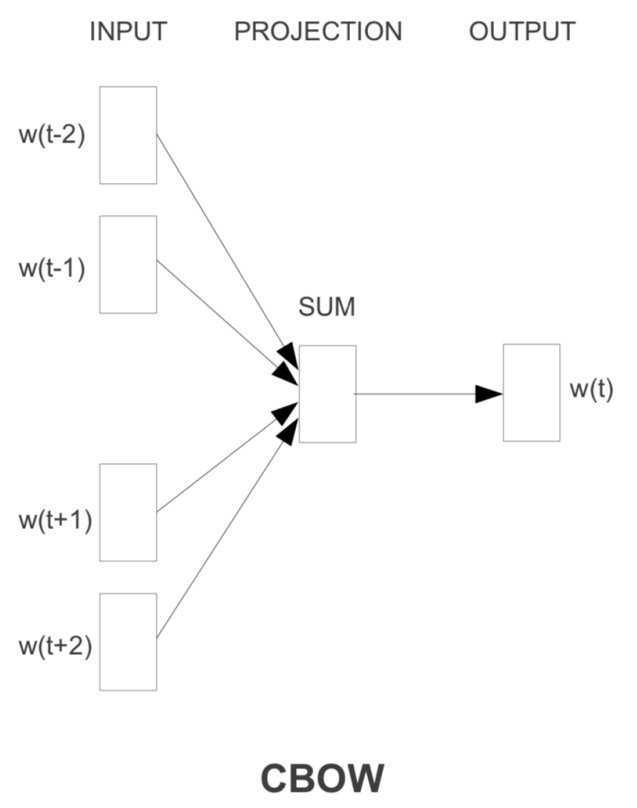

Figure 2.6: CBOW model.

For this thesis, we focused on the CBOW model. The input layer for the CBOW model is a sparse one hot encoded vector. This vector is of size $\mathrm{N}$, where $\mathrm{N}$ is the number of words in their vocabulary and each input neuron represents a single word. The hidden layer is of size $\mathrm{P}$ and ranges between 50-300 neurons. The output layer is identical to the input layer but the output of each neuron is the probability that the word is the target word. The most important part of this network are the embeddings. These embeddings are extracted from the hidden layer by multiplying the output of the neurons by their weights. The embeddings are valuable because they can transform a sparse dataset into a more dense dataset with significantly fewer features. While both the Skipgram and CBOW models were unable to consistently predict the target or context words, Mikolov et al. found the embeddings captured relationships and similarities between words and it allowed them to represent words as continuous vectors. From these embeddings, they found that similar words were grouped together and similar relationships between words were represented in the same way, such as the distances between gender specific terms. For example, given 
the vector for "king", if you were to subtract the vector "man" and add the vector "woman", it would be almost equivalent to the vector "queen".

\subsection{Principal Component Analysis}

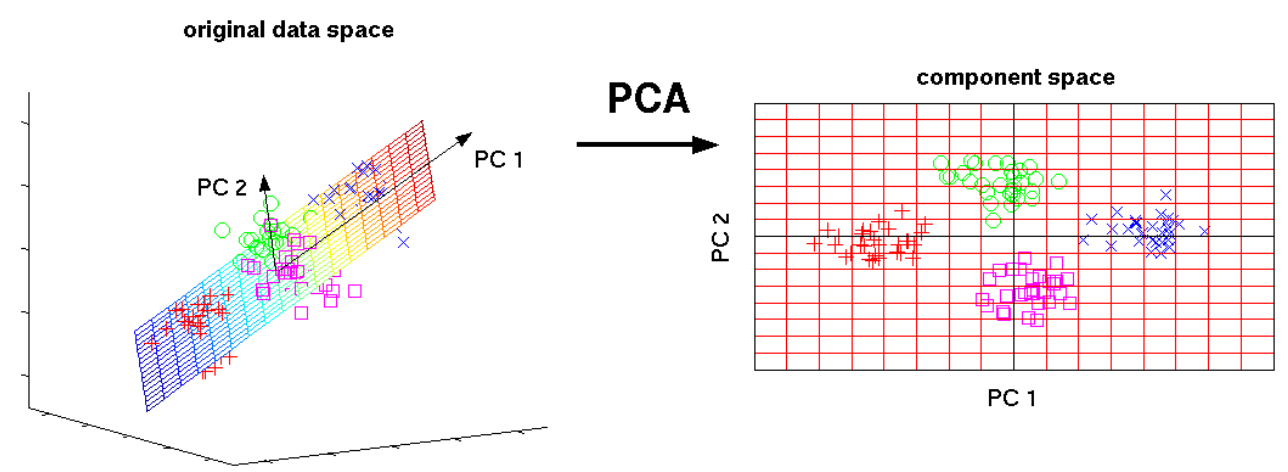

\section{Figure 2.7: Example of PCA reducing 3 dimensions to 2 dimension.}

Principal component analysis (PCA)[18] is a way of summarizing high dimensional data in lower dimensions. When given a set of attributes that describe a data set, some of the features may be redundant while some features may accurately describe the differences over all of the observations. PCA creates new features for the data, projected in a $\mathrm{N}$ lower dimension. The new features are created from a mathematical combination of $\mathrm{N}$ features which are responsible for the highest variance over all observations.

\subsection{Latent Dirichlet Allocation}

Latent Dirichlet Allocation (LDA) is a way of automatically finding topics within a corpus of documents. LDA is able to do this in four steps. First, a number of topics is selected, N. Second, each word is randomly assigned a topic. Third, for each word, LDA looks at the word's occurrence in the topic and the number of topics in the document and updates the topic based on the probability that the word is in the given topic. Finally, each document is assigned a mixture of topics based on the ratio 
of topics assigned to each word. For example, a document could be 30\% topic 1 and $70 \%$ topic 2 . In this thesis, we used LDA to assign a single topic to each bill. The topic that was selected was the topic with the highest percent.

\subsection{Software Packages}

In this thesis, we used several python packages during our data extraction process. The following section will describe these packages and why we chose to use them.

\subsubsection{Pandas}

All the extraction, transfer, and load processes were handled using the software package Pandas[13]. Pandas allows us to perform all formatting operations on the data in code rather than in MySQL. We found that it was substantially faster to perform unstructured queries and format them with Pandas than formatting the data using more complex MySQL queries.

\subsubsection{TextBlob}

To extract features such as the number of words, nouns and adjectives, we used the TextBlob text processing package[16], which can identify each word's part of speech. While TextBlob can also provide a sentiment score, we found that the Vader sentiment package provided better results.

\subsubsection{Vader Sentiment}

We used Vader, a sentiment analysis tool that specializes in short, to analyze the sentiment of a legislators speech[17]. We found that Vader was able to sufficiently analyze our legislator utterances. 


\section{Chapter 3}

\section{RELATED WORK}

Predicting a state legislator's level of activity or participation in a bill's life-cycle based on an incoming bill and a legislator's previous history has not been attempted before. Kraft et al. created a model that predicted roll call votes from bill text[26]. Their model achieved an average of $90.7 \%$ accuracy. In the first paper, Kraft et al. built a model based on the federal legislature while ours is focused on the California state legislature. Kraft el al.'s model only focused on bills that were passed through a roll call vote while we used every committee vote and floor vote to build our model. Similarly, Kornilova et al. carried out a research study on roll-call vote using data over several sessions. Their model was able to incorporate metadata about a legislators ideologies over time [25]. This paper shows a $4 \%$ improvement over existing methods by incorporating embeddings into their system. In both Kornilov et al. and Kraft et al.'s experiments, the only legislator behavioral meta-data was politcal ideology. In our experiments, we show that using a combination of bill data and legislator behavioral meta-data to create embeddings has promise. Futhermore, our study is a first of it's kind analysis since it focuses on state legislatures. Another study done by Iyyer et al., uses word embeddings and recusive neural networks to identify political ideologies in text [23]. The results in this study show the authors were able to out perform existing methods. In this study, the authors use word embeddings as input into their model as oppose to our goal of creating new embeddings. In a cross sectional study, Cohen et al. [20] created a priori factor model to identify a legislator's support of the tobacco industry in Canada. Cohen et al.'s work was based in Canada and only focused on identifying legislator support toward bills related to the tobacco industry.

Because of the success from Word2Vec, many different projects have used it's model as an inspiration for a model of their own. For example, Quoc V. Le and 
Tomas Mikolov wrote a paper called Distributed Representations of Sentences and Documents [27], commonly know as Doc2Vec. In this paper, Mikolov et al. introduce Paragraph Vectors. These vector are able to represent documents in a dense feature space. To do this, Mikolov et al. trained a model to predict missing words within the document. The authors goal was to capture ordering and semantic meaning of words within sentences.

Another project which stemmed from Word2Vec is Node2Vec: Scalable Feature Learning for Networks [22]. Researchers, Aditya Grover and Jure Leskovec, had a goal of learning feature representations of nodes in networks. To do this, Node2Vec tries to maximize the likelihood of preserving network neighborhoods. From this, Node2Vec is able to represent network nodes in a low dimensional feature space.

The last Word2Vec project we will mention is Location2Vec [31]. In Location2Vec: Generating Distributed Representation of Location by Using Geo-tagged Microblog Posts, Shoji et al. attempt to represent a location in a low dimensional feature space using microblogs. Using a shallow neural network, Shoji et al. tried to predict missing words from microblogs, such as tweets. While Doc2Vec, Node2Vec, and Location2Vec draw inspiration from Word2Vec, their domains are completely different from our system.

As previously mentioned, Digital Democracy has an extremely rich data set that has been applied to a variety of research problems. In an earlier thesis, Andrew Wang developed the TONGS (TLDR; Opinion Network Guide System) library for conducting sentiment analysis[33]. This library uses TensorFlow's Word2Vec to convert words into a vector space representation. This library showed significant improvements over traditional sentiment analysis libraries by looking at a variety of different descriptive data sources related to the legislator. While this thesis uses sentiment analysis, our sentiment feature does not heavily depend on precise measurements of sentiment.

Christopher Wu's thesis, Sentiment Knowledge Extraction With Entity Recog- 
nition (SKEWER), is another work built around Digital Democracy[34] that extends the capabilities of TONGS. SKEWER is a pipeline for extracting sentiment and entities from a given text. Wu found that SKEWER is extremely proficient at recognizing entities within a person's speech. Specifically, it extracts lobbyists, organizations, and a speaker's identity during committee meetings. Our work uses legislators' speech as a feature; their identities were known throughout the process.

In September of 2017, Daniel Kauffman built a system that used a legislator's utterance to determine their alignment toward a known entity[24]. This allowed users to predict a legislator's alignment with specific organizations with know views. While we do use utterance data in this thesis, we do not look at external organization. Additionally, this research does not use the Digital Democracy project's alignment data.

In March of 2018, Aditya Budhwar tried to predict a legislators vote by examining their speech prior to a vote[19]. In this thesis, we also analyzed a legislator speech prior to voting using a less in-depth methodology. While we used similar methods to [19], the objective of our work is completely different. For the scope of this thesis, we needed to analyze whether or not the legislator had a non-neutral sentiment and collected features about the amount of time a legislator spent speaking on a bill. The objective of [19] was to predict a legislator's vote completely dependent on only features related to a legislator's speech. 
Chapter 4

THE LEGISLATOR'S ACTIVITY ON BILLS (LAB) DATASET

\subsection{The Digital Democracy Project Database Overview}

All of the data for this thesis was provided by the Digital Democracy project. The Digital Democracy project's database (DDDB) aggregates several different data sources into one database. These data sources include FollowTheMoney[4], LegInfo[9], Maplight[10], and OpenStates [11]. The data is then used to power the Digital Democracy project's website and research platform. A few examples of data that is stored in the DDDB are: a legislators name, party affiliation, and district, all information about committee memberships, the full text and voting records of each bill, and full transcriptions of every utterance said during a committee hearing along with the speaker information.

\subsection{Extraction Methods}

For this thesis, we extracted all of our features from the California State Legislature 2015-2016 session in the DDDB. We extracted as many features as possible that accurately and uniquely describe a legislator, a bill, and a legislator's activity on a bill. To do this, we would executed generic queries with relative few filters through a Python client. After reading the result into a Pandas DataFrame, we would extracted existing features or create a new features from the DataFrame. For example, if we extracted the user ID, the start time stamp of an utterance, and the end time stamp of an utterance, we could subtract the end time stamp from the start time stamp then aggregate our result per user to get the total time a user spoke. Overall, our features are sorted into three categories: legislator, bill, and a legislator's activity on a bill. 


\subsection{Legislator Features}

For each legislator, our goal was to find static features that uniquely summarized the legislator over an entire session. This includes features such as the legislators party and the number of committees they were a member of. Table 4.1 presents the full list of legislator features.

\begin{tabular}{|c|c|c|c|}
\hline Attribute & Description & Data Type & $\begin{array}{l}\text { Feature } \\
\text { Shape }\end{array}$ \\
\hline Party & $\begin{array}{l}\text { The party of the legislator: Democrat or } \\
\text { Republican. }\end{array}$ & $\begin{array}{l}\text { One-hot encoded } \\
\text { vectors. }\end{array}$ & $120 \times 2$ \\
\hline House & $\begin{array}{l}\text { The house where the legislator resides: As- } \\
\text { sembly or Senate. }\end{array}$ & $\begin{array}{l}\text { One-hot encoded } \\
\text { vectors. }\end{array}$ & $120 \times 2$ \\
\hline District & The Assembly or Senate district number. & $\begin{array}{l}\text { One-hot encoded } \\
\text { vectors (120 val- } \\
\text { ues). }\end{array}$ & $120 \times 2$ \\
\hline $\begin{array}{l}\text { Total Bill Dis- } \\
\text { cussions }\end{array}$ & $\begin{array}{l}\text { The number of bill discussions a legislator } \\
\text { attended. }\end{array}$ & Numeric. & $120 \times 1$ \\
\hline $\begin{array}{l}\text { Total Bill Dis- } \\
\text { cussion by Topic }\end{array}$ & $\begin{array}{l}\text { The number of bill discussions a legislator } \\
\text { attended split by the topic of a bill. }\end{array}$ & Numeric. & $120 \times 30$ \\
\hline $\begin{array}{l}\text { Average Utter- } \\
\text { ance Time }\end{array}$ & $\begin{array}{l}\text { The average time a legislator speaks per } \\
\text { utterance. }\end{array}$ & $\begin{array}{l}\text { Numeric in sec- } \\
\text { onds. }\end{array}$ & $120 \times 1$ \\
\hline $\begin{array}{l}\text { Total Speaking } \\
\text { Time }\end{array}$ & $\begin{array}{l}\text { The total time a legislator spent speaking } \\
\text { on bills. }\end{array}$ & $\begin{array}{l}\text { Numeric in sec- } \\
\text { onds. }\end{array}$ & $120 \times 1$ \\
\hline $\begin{array}{l}\text { Total Author- } \\
\text { ships }\end{array}$ & $\begin{array}{l}\text { The number of times a legislator authored } \\
\text { a bill. }\end{array}$ & Numeric. & $120 \times 1$ \\
\hline
\end{tabular}




\begin{tabular}{|c|c|c|c|}
\hline $\begin{array}{l}\text { Committee } \\
\text { Membership: } \\
\text { Member }\end{array}$ & $\begin{array}{l}\text { The number of committees a legislator } \\
\text { served on as a member. }\end{array}$ & Numeric. & $120 \times 1$ \\
\hline $\begin{array}{l}\text { Committee } \\
\text { Membership: } \\
\text { Co-Chair }\end{array}$ & $\begin{array}{l}\text { The number of committees a legislator } \\
\text { served on as a co-chair. }\end{array}$ & Numeric. & $120 \times 1$ \\
\hline $\begin{array}{l}\text { Committee } \\
\text { Membership: } \\
\text { Vice-Chair }\end{array}$ & $\begin{array}{l}\text { The number of committees a legislator } \\
\text { served on as a vice-chair. }\end{array}$ & Numeric. & $120 \times 1$ \\
\hline $\begin{array}{l}\text { Committee } \\
\text { Membership: } \\
\text { Chair }\end{array}$ & $\begin{array}{l}\text { The number of committees a legislator } \\
\text { served on as the committee chair. }\end{array}$ & Numeric. & $120 \times 1$ \\
\hline Total Ayes & $\begin{array}{l}\text { The total number of times a legislator } \\
\text { voted aye during the entire session. }\end{array}$ & Numeric. & $120 \times 1$ \\
\hline Total Noes & $\begin{array}{l}\text { The total number of times a legislator } \\
\text { voted noe during the entire session. }\end{array}$ & Numeric. & $120 \times 1$ \\
\hline Total ABS & $\begin{array}{l}\text { The total number of times a legislator ab- } \\
\text { stained from voting during the entire ses- } \\
\text { sion. }\end{array}$ & Numeric. & $120 \times 1$ \\
\hline Total Votes & $\begin{array}{l}\text { The total number of times a legislator } \\
\text { voted on a bill during the entire session. }\end{array}$ & Numeric. & $120 \times 1$ \\
\hline $\begin{array}{l}\text { Average Bill Dis- } \\
\text { cussion Time }\end{array}$ & $\begin{array}{l}\text { The average time a legislator spent speak- } \\
\text { ing during a bill discussion. }\end{array}$ & $\begin{array}{l}\text { Numeric in sec- } \\
\text { onds. }\end{array}$ & $120 \times 1$ \\
\hline $\begin{array}{l}\text { Committee } \\
\text { Membership }\end{array}$ & Which committees a legislator serves on. & $\begin{array}{l}\text { A single one-hot } \\
\text { encoded vector } \\
\text { per committee. }\end{array}$ & $120 \times 71$ \\
\hline
\end{tabular}




\begin{tabular}{|c|c|c|c|}
\hline Voted with Party & $\begin{array}{l}\text { The number of times a legislator voted } \\
\text { with the majority of their party. }\end{array}$ & Numeric. & $120 \times 1$ \\
\hline $\begin{array}{l}\text { Total votes } \\
\text { against party }\end{array}$ & $\begin{array}{l}\text { The number of times a legislator voted } \\
\text { against the majority of their party. }\end{array}$ & Numeric. & $120 \times 1$ \\
\hline $\begin{array}{l}\text { Total Bill Dis- } \\
\text { cussions as Com- } \\
\text { mittee Member }\end{array}$ & $\begin{array}{l}\text { The number of bill discussions a legislator } \\
\text { attended as a committee member. }\end{array}$ & Numeric. & $120 \times 1$ \\
\hline $\begin{array}{l}\text { Total Bill Dis- } \\
\text { cussions not } \\
\text { as Committee } \\
\text { Member }\end{array}$ & $\begin{array}{l}\text { The number of bill discussions a legislator } \\
\text { attended not as a committee member. }\end{array}$ & Numeric. & $120 \times 1$ \\
\hline $\begin{array}{l}\text { Total Bill Dis- } \\
\text { cussion as Bill } \\
\text { Sponsor }\end{array}$ & $\begin{array}{l}\text { The number of bill discussions a legislator } \\
\text { attended as a sponsor. }\end{array}$ & Numeric. & $120 \times 1$ \\
\hline $\begin{array}{l}\text { Total Bill Dis- } \\
\text { cussion not as } \\
\text { Bill Sponsor }\end{array}$ & $\begin{array}{l}\text { The number of bill discussions a legislator } \\
\text { attended not as a sponsor. }\end{array}$ & Numeric. & $120 \times 1$ \\
\hline Total Utterances & $\begin{array}{l}\text { The number of utterances a legislator had } \\
\text { over the entire session. }\end{array}$ & Numeric. & $120 \times 1$ \\
\hline $\begin{array}{l}\text { Total Utterances } \\
\text { as a Committee } \\
\text { Member }\end{array}$ & $\begin{array}{l}\text { The number of utterances a legislator had } \\
\text { over the entire session as a committee } \\
\text { member. }\end{array}$ & Numeric. & $120 \times 1$ \\
\hline $\begin{array}{l}\text { Total Utterances } \\
\text { not as a Com- } \\
\text { mittee Member }\end{array}$ & $\begin{array}{l}\text { The number of utterances a legislator had } \\
\text { over the entire session not as a committee } \\
\text { member. }\end{array}$ & Numeric. & $120 \times 1$ \\
\hline
\end{tabular}




\begin{tabular}{|l|l|l|l|}
\hline Average Bill & The average time a legislator spent speak- & Numeric. & $120 \times 2$ \\
Discussion Time & ing on bills that passed/failed. & & \\
based on bill & & & $120 \times 30$ \\
result & & Numeric. & \\
\hline $\begin{array}{l}\text { Average Bill } \\
\text { Discussion Time }\end{array}$ & ing on bills per topic. & & \\
based on bill & & & \\
topic
\end{tabular}

Table 4.1: Legislator Features

\subsection{Bill Features}

The bill features contain information that describs the contents of the bill and the status of the bill as it passed through its life cycle. Some features include the topic of the bill, the number of bill versions, and summary information about the voting. These bill features were independent of the legislators and can not be correlated with any of them.

\begin{tabular}{|l|l|l|l|}
\hline \hline Attribute & Description & Data Type & Feature \\
& & & Shape \\
\hline \hline Chamber Origin & $\begin{array}{l}\text { The chamber where the bill originated } \\
\text { from: Assembly, Senate, or Joint. }\end{array}$ & One-hot encoded & $686 \times 3$ \\
\hline Bill Status & The final status of the bill. & One-hot en- & $686 \times 8$ \\
\hline Assembly Hear- & The number of assembly committee hear- & Numeric. & $686 \times 1$ \\
\hline ings & ings. & & $686 \times 1$ \\
\hline
\end{tabular}




\begin{tabular}{|c|c|c|c|}
\hline Joint Hearings & The number of joint committee hearings. & Numeric. & $686 \times 1$ \\
\hline $\begin{array}{l}\text { Abstain: Demo- } \\
\text { crat }\end{array}$ & $\begin{array}{l}\text { The number of Democratic legislators that } \\
\text { abstained from voting on the bill. }\end{array}$ & Numeric. & $686 \times 1$ \\
\hline $\begin{array}{l}\text { Abstain: Repub- } \\
\text { lican }\end{array}$ & $\begin{array}{l}\text { The number of Republican legislators that } \\
\text { abstained from voting on the bill. }\end{array}$ & Numeric. & $686 \times 1$ \\
\hline Aye: Democrat & $\begin{array}{l}\text { The number of Democrat legislators that } \\
\text { voted Aye on the bill. }\end{array}$ & Numeric. & $686 \times 1$ \\
\hline Aye: Republican & $\begin{array}{l}\text { The number of Republican legislators that } \\
\text { voted Aye on the bill. }\end{array}$ & Numeric. & $686 \times 1$ \\
\hline Noe: Democrat & $\begin{array}{l}\text { The number of Democrat legislators that } \\
\text { voted Aye on the bill. }\end{array}$ & Numeric. & $686 \times 1$ \\
\hline Noe: Republican & $\begin{array}{l}\text { The number of Republican legislators that } \\
\text { voted Aye on the bill. }\end{array}$ & Numeric. & $686 \times 1$ \\
\hline Topic & The topic of the bill text. & $\begin{array}{l}\text { One-hot } \\
\text { coded. }\end{array}$ & $686 \times 30$ \\
\hline Total Ayes & The total number of aye votes on the bill. & Numeric. & $686 \times 1$ \\
\hline Total Noes & The total number of noe votes on the bill. & Numeric. & $686 \times 1$ \\
\hline Total ABS & $\begin{array}{l}\text { The total number of legislator that ab- } \\
\text { stained from voting on the bill. }\end{array}$ & Numeric. & $686 \times 1$ \\
\hline Number of words & $\begin{array}{l}\text { The total number of words on the final ver- } \\
\text { sion of the bill. }\end{array}$ & Numeric. & $686 \times 1$ \\
\hline $\begin{array}{l}\text { Number of ver- } \\
\text { sions }\end{array}$ & $\begin{array}{l}\text { The number of version the bill went } \\
\text { through. }\end{array}$ & Numeric. & $686 \times 1$ \\
\hline $\begin{array}{l}\text { Number of bills } \\
\text { passed per topic }\end{array}$ & $\begin{array}{l}\text { The number of bills that passed (Chapter } \\
\text { or Enrolled) per topic }\end{array}$ & $\begin{array}{l}\text { A Numeric per } \\
\text { topic. }\end{array}$ & $686 \times 30$ \\
\hline
\end{tabular}




\begin{tabular}{|l|l|l|l|}
\hline $\begin{array}{l}\text { Number of bills } \\
\text { failed per topic }\end{array}$ & $\begin{array}{l}\text { The number of bills that failed (Neither } \\
\text { Chaptered nor Enrolled) per topic }\end{array}$ & $\begin{array}{l}\text { A Numeric per } \\
\text { topic. }\end{array}$ & $686 \times 30$ \\
\hline $\begin{array}{l}\text { Number of bills } \\
\text { passed per com- } \\
\text { mittee }\end{array}$ & $\begin{array}{l}\text { The number of bills that passed per com- } \\
\text { mittee. }\end{array}$ & $\begin{array}{l}\text { A Numeric per } \\
\text { committee. }\end{array}$ & $686 \times 71$ \\
\hline $\begin{array}{l}\text { Number of bills } \\
\text { failed per com- } \\
\text { mittee }\end{array}$ & $\begin{array}{l}\text { The number of bills that failed per com- } \\
\text { mittee. }\end{array}$ & $\begin{array}{l}\text { A Numeric per } \\
\text { committee. }\end{array}$ & $686 \times 71$ \\
\hline $\begin{array}{l}\text { Number of utter- } \\
\text { ances per topic }\end{array}$ & The total number of utterances per topic. & $\begin{array}{l}\text { A Numeric per } \\
\text { topic. }\end{array}$ & $686 \times 30$ \\
\hline $\begin{array}{l}\text { Number of utter- } \\
\text { ances per topic } \\
\text { passed. }\end{array}$ & $\begin{array}{l}\text { The total number of utterances per topic } \\
\text { for bills that passed. }\end{array}$ & $\begin{array}{l}\text { A Numeric per } \\
\text { topic. }\end{array}$ & $686 \times 30$ \\
\hline $\begin{array}{l}\text { Number of utter- } \\
\text { ances per topic } \\
\text { failed }\end{array}$ & $\begin{array}{l}\text { The total number of utterances per topic } \\
\text { for bills that failed. }\end{array}$ & $\begin{array}{l}\text { A Numeric per } \\
\text { topic. }\end{array}$ & $686 \times 30$ \\
\hline $\begin{array}{l}\text { Number of bill } \\
\text { discussions per } \\
\text { topic }\end{array}$ & $\begin{array}{l}\text { The total number of bill discussions per } \\
\text { topic. }\end{array}$ & $\begin{array}{l}\text { A Numeric per } \\
\text { topic. }\end{array}$ & $686 \times 30$ \\
\hline $\begin{array}{l}\text { Number of bill } \\
\text { discussions per } \\
\text { topic passed. }\end{array}$ & topic for bills that passed. & A Numeric per \\
\hline $\begin{array}{l}\text { Number of bill } \\
\text { discussions per } \\
\text { topic failed }\end{array}$ & $\begin{array}{l}\text { The total number of bill discussions per } \\
\text { topic for bills that failed. }\end{array}$ & $\begin{array}{l}\text { A Numeric per } \\
\text { topic. }\end{array}$ & $686 \times 30$ \\
\hline
\end{tabular}




\begin{tabular}{|c|c|c|c|}
\hline $\begin{array}{l}\text { Number of com- } \\
\text { mittee hearings } \\
\text { per topic }\end{array}$ & $\begin{array}{l}\text { The total number of committee hearings } \\
\text { per topic. }\end{array}$ & $\begin{array}{l}\text { A Numeric per } \\
\text { topic. }\end{array}$ & $686 \times 30$ \\
\hline $\begin{array}{l}\text { Number of com- } \\
\text { mittee hearings } \\
\text { per topic passed. }\end{array}$ & $\begin{array}{l}\text { The total number of committee hearings } \\
\text { per topic for bills that passed. }\end{array}$ & $\begin{array}{l}\text { A Numeric per } \\
\text { topic. }\end{array}$ & $686 \times 30$ \\
\hline $\begin{array}{l}\text { Number of com- } \\
\text { mittee hearings } \\
\text { per topic failed }\end{array}$ & $\begin{array}{l}\text { The total number of committee hearings } \\
\text { per topic for bills that failed. }\end{array}$ & $\begin{array}{l}\text { A Numeric per } \\
\text { topic. }\end{array}$ & $686 \times 30$ \\
\hline $\begin{array}{l}\text { Aye votes per } \\
\text { topic }\end{array}$ & The number of aye votes per topic & $\begin{array}{l}\text { A Numeric per } \\
\text { topic. }\end{array}$ & $686 \times 30$ \\
\hline $\begin{array}{l}\text { Noe votes per } \\
\text { topic }\end{array}$ & The number of noe votes per topic & $\begin{array}{l}\text { A Numeric per } \\
\text { topic. }\end{array}$ & $686 \times 30$ \\
\hline $\begin{array}{l}\text { Abstain votes } \\
\text { per topic }\end{array}$ & $\begin{array}{l}\text { The number of legislators that abstained } \\
\text { from voting per topic. }\end{array}$ & $\begin{array}{l}\text { A Numeric per } \\
\text { topic. }\end{array}$ & $686 \times 30$ \\
\hline $\begin{array}{l}\text { Mean Aye votes } \\
\text { per topic }\end{array}$ & The mean number of aye votes per topic & $\begin{array}{l}\text { A Numeric per } \\
\text { topic. }\end{array}$ & $686 \times 30$ \\
\hline $\begin{array}{l}\text { Mean Noe votes } \\
\text { per topic }\end{array}$ & The mean number of noe votes per topic & $\begin{array}{l}\text { A Numeric per } \\
\text { topic. }\end{array}$ & $686 \times 30$ \\
\hline $\begin{array}{l}\text { Mean Abstain } \\
\text { votes per topic }\end{array}$ & $\begin{array}{l}\text { The mean number of legislators that ab- } \\
\text { stained from voting per topic. }\end{array}$ & $\begin{array}{l}\text { A Numeric per } \\
\text { topic. }\end{array}$ & $686 \times 30$ \\
\hline $\begin{array}{l}\text { Total time spent } \\
\text { talking on each } \\
\text { topic passed bills }\end{array}$ & $\begin{array}{l}\text { The total amount of time spent talking on } \\
\text { bills that passed. }\end{array}$ & $\begin{array}{l}\text { A Numeric per } \\
\text { topic. }\end{array}$ & $686 \times 30$ \\
\hline
\end{tabular}




\begin{tabular}{|l|l|l|l|}
\hline $\begin{array}{l}\text { Total time spent } \\
\text { talking on each } \\
\text { topic failed bills }\end{array}$ & bills that failed. & A Numeric per & $686 \times 30$ \\
\hline $\begin{array}{l}\text { Average time } \\
\text { spent talking }\end{array}$ & The average amount of time spent talking & A Numeric per & $686 \times 30$ \\
on each topic & topic. & \\
passed bills & The average amount of time spent talking & A Numeric per & $686 \times 30$ \\
\hline $\begin{array}{l}\text { Average time } \\
\text { spent talking on }\end{array}$ & on bills that failed. & topic. & \\
each topic failed & & & \\
bills & & & \\
\hline
\end{tabular}

Table 4.2: Bill Features

\subsection{Activity Features}

The activity feature set includes any action or description of an action a legislator can perform on a bill. This means that for each bill, we have an observation for each legislator. These activity features include whether or not the legislator was the author of the bill and how long the legislator spoke on a bill.

\begin{tabular}{|l|l|l|l|}
\hline \hline Attribute & Description & Data Type & $\begin{array}{l}\text { Feature } \\
\text { Shape }\end{array}$ \\
\hline \hline Author & $\begin{array}{l}\text { Whether or not the legislator was the au- } \\
\text { thor of the bill. }\end{array}$ & One-hot encoded $83006 \mathrm{x}$ \\
vector. & 2 \\
\hline Shared Chamber & $\begin{array}{l}\text { The bill originates in the same house as the } \\
\text { author. }\end{array}$ & One-hot encoded $83006 \mathrm{x}$ \\
\hline
\end{tabular}




\begin{tabular}{|c|c|c|c|}
\hline Utterances & $\begin{array}{l}\text { The number of utterances a legislator } \\
\text { spoke on a bill. }\end{array}$ & Numeric. & $\begin{array}{l}83006 \mathrm{x} \\
1\end{array}$ \\
\hline $\begin{array}{l}\text { Utterances as } \\
\text { a Committee } \\
\text { Member }\end{array}$ & $\begin{array}{l}\text { The number of utterances a legislator } \\
\text { spoke on a bill as a committee member. }\end{array}$ & Numeric. & $\begin{array}{l}83006 \mathrm{x} \\
1\end{array}$ \\
\hline $\begin{array}{l}\text { Utterances not } \\
\text { as Committee } \\
\text { Member }\end{array}$ & $\begin{array}{l}\text { The number of utterances a legislator } \\
\text { spoke on a bill not as a committee member. }\end{array}$ & Numeric. & $\begin{array}{l}83006 \mathrm{x} \\
1\end{array}$ \\
\hline $\begin{array}{l}\text { Number of } \\
\text { Words }\end{array}$ & $\begin{array}{l}\text { The number of words a legislator spoke on } \\
\text { a bill. }\end{array}$ & Numeric. & $\begin{array}{l}83006 \mathrm{x} \\
1\end{array}$ \\
\hline Number of nouns & $\begin{array}{l}\text { The number of nouns a legislator spoke on } \\
\text { a bill. }\end{array}$ & Numeric. & $\begin{array}{l}83006 \mathrm{x} \\
1\end{array}$ \\
\hline Number of verbs & $\begin{array}{l}\text { The number of verbs a legislator spoke on } \\
\text { a bill. }\end{array}$ & Numeric. & $\begin{array}{l}83006 \mathrm{x} \\
1\end{array}$ \\
\hline $\begin{array}{l}\text { Number of adjec- } \\
\text { tives }\end{array}$ & $\begin{array}{l}\text { The number of adjectives a legislator spoke } \\
\text { on a bill. }\end{array}$ & Numeric. & $\begin{array}{l}83006 \mathrm{x} \\
1\end{array}$ \\
\hline Average Polarity & $\begin{array}{l}\text { The average polarity score of a legislators } \\
\text { utterances. }\end{array}$ & Numeric. & $\begin{array}{l}83006 \mathrm{x} \\
1\end{array}$ \\
\hline $\begin{array}{l}\text { Average Subjec- } \\
\text { tivity }\end{array}$ & $\begin{array}{l}\text { The average subjectivity score of a legisla- } \\
\text { tors utterances. }\end{array}$ & Numeric. & $\begin{array}{l}83006 \mathrm{x} \\
1\end{array}$ \\
\hline Overall Polarity & $\begin{array}{l}\text { The overall polarity score of a legislators } \\
\text { utterances. }\end{array}$ & Numeric. & $\begin{array}{l}83006 \mathrm{x} \\
1\end{array}$ \\
\hline $\begin{array}{l}\text { Overall Subjec- } \\
\text { tivity }\end{array}$ & $\begin{array}{l}\text { The overall subjectivity score of a legisla- } \\
\text { tors utterances. }\end{array}$ & Numeric. & $\begin{array}{l}83006 \mathrm{x} \\
1\end{array}$ \\
\hline $\begin{array}{l}\text { Percent Voted } \\
\text { Aye }\end{array}$ & $\begin{array}{l}\text { The proportion of votes a legislator voted } \\
\text { aye. }\end{array}$ & Numeric. & $\begin{array}{l}83006 \mathrm{x} \\
1\end{array}$ \\
\hline
\end{tabular}




\begin{tabular}{|c|c|c|c|}
\hline Notes & $\begin{array}{l}\text { The number of times a legislator voted on } \\
\text { a bill. }\end{array}$ & Numeric. & $\begin{array}{l}83006 x \\
1\end{array}$ \\
\hline Bill Discussions & $\begin{array}{l}\text { The number of bills discussions a legislator } \\
\text { attended for a bill. }\end{array}$ & Num & $\begin{array}{l}83006 \mathrm{x} \\
1\end{array}$ \\
\hline Voted with Party & $\begin{array}{l}\text { Whether or not a legislator voted with the } \\
\text { majority of their party. }\end{array}$ & $\begin{array}{l}\text { One-hot encoded } \\
\text { vector. }\end{array}$ & $\begin{array}{l}83006 x \\
2\end{array}$ \\
\hline Speaking Time & Total time spent speaking on a bill. & $\begin{array}{l}\text { Numeric in sec- } \\
\text { onds. }\end{array}$ & $\begin{array}{l}83006 x \\
1\end{array}$ \\
\hline $\begin{array}{l}\text { Average Utter- } \\
\text { ance Time }\end{array}$ & $\begin{array}{l}\text { The average length of a legislator's utter- } \\
\text { ances on a bill. }\end{array}$ & $\begin{array}{l}\text { Numeric in sec- } \\
\text { onds. }\end{array}$ & $\begin{array}{l}83006 \mathrm{x} \\
1\end{array}$ \\
\hline $\begin{array}{l}\text { Average Bill Dis- } \\
\text { cussion Time }\end{array}$ & $\begin{array}{l}\text { The average time a legislator spent speak- } \\
\text { ing at each bill discussion for a bill. }\end{array}$ & $\begin{array}{l}\text { Numeric in sec- } \\
\text { onds. }\end{array}$ & $\begin{array}{l}83006 \mathrm{x} \\
1\end{array}$ \\
\hline
\end{tabular}

Table 4.3: Participation Features 
Chapter 5

DEMOCRACY2VEC

This chapter describes our custom model and techniques we used to filter our training data. We propose Democracy2Vec, a novel neural network implementation that draws inspiration from Googles Word2Vec. The objective of our network is to create embeddings that represent how active a legislator will be during a bill's life cycle and how they will likely act on that bill.

\subsection{Data Filtering}

While building this network, we found that there were several factors that made our data set unbalanced. This section describes these factor and how we attempted to balance our data set with filtering techniques.

\subsubsection{Voting Percentage}

Within both chambers of the California State Legislature, there are 42 Republicans and 78 Democrats. The Assembly is comprised of 52 Democrats and 28 Republicans, while the Senate has 26 Democrats and 14 Republicans. In both chambers, Democrats control $65 \%$ of the seats which means they can push legislation through when the legislators vote along party lines. We found that there is less legislator activity on bills that followed party lines. Additionally, the legislative body passes a lot of bills with a unanimous vote. These bills are not controversial, and therefore there is little to no debate on them. Because of these factors, we required that all bills in our training set have less than $70 \%$ voter agreement. To do this, we take the max between the total number of aye, abstain, and noe votes, divide by the total votes and check if that proportion is less than $70 \%$. This requirement allowed us to look at bills with higher legislative activity where legislators broke party lines. 


\subsubsection{Unique Voters}

During the session year, there are a lot of bills that die before leaving their committee(s). These bills cause our voting attributes to become sparse. To reduce the sparse data, we filtered out bills that did not have at least 60 unique voters, which guarantees the bill has been voted on by at least half of the legislative body.

\subsubsection{Feature Reduction}

During our training process, we found that a lot of our features had a negative effect on our embeddings and/or accuracy measurements. The reason some these features had such an affect was that our network was extremely shallow and we had very few observations. Due to these factors, it is difficult for our network to learn and incorporate complicated features (i.e., features split by topic). We found that the remaining features accurately and uniquely describe legislators, bills, and legislator activity. Table 5.1 describes the feature set used in our final model.

\begin{tabular}{|l|l|}
\hline \hline Attribute & Type \\
\hline \hline Total Authorships & Legislator \\
\hline Party & Legislator \\
\hline Chamber & Legislator \\
\hline Number of Committee Positions & Legislator \\
\hline Bill Chamber Origin & Bill \\
\hline Bill Status & Bill \\
\hline Number of Bill Hearings & Bill \\
\hline Number of Bill Hearings per Chamber & Bill \\
\hline Votes Broken Down by Party & Bill \\
\hline Overall Votes & Bill \\
\hline Bill Topic & Bill \\
\hline
\end{tabular}




\begin{tabular}{|l|l|}
\hline Number of Bill Discussions & Bill \\
\hline Average Utterance Length for a Bill & Bill \\
\hline Sponsorship Type & Bill \\
\hline Number of Utterances as Committee Member & Bill \\
\hline Number of Utterances not as Committee Member & Bill \\
\hline Overall Sentiment & Activity \\
\hline Average Sentiment & Activity \\
\hline The number of utterances said on a bill & Activity \\
\hline The number of words said on a bill & Activity \\
\hline The average number of words said during utterances & Activity \\
\hline Total time spent speaking on a bill & Activity \\
\hline The number of times a legislator voted aye & Activity \\
\hline The number of nounds, adjectives, and verbs said by a legislator & Activity \\
\hline Broke party lines on vote & Activity \\
\hline Average time spent speaking during bill discussions & Activity \\
\hline Is the legislator the Author & Activity \\
\hline Do the legislator and bill share the chamber of origin & Activity \\
\hline The number of votes a legislator took & Activity \\
\hline
\end{tabular}

Table 5.1: Final Feature Set

\subsection{Network Motivation}

As stated above, this network draws inspiration from Googles Word2Vec network. Our original idea for this network was given a set of input's from our legislator and bill features, predict a feature from our activity features. This allows us to predict on new incoming bills where the activity features are missing. After creating this 
network, we found that the embeddings were not meaningful and did not describe any relationships in our data. The issue for was that most of our features are static. Given that there are only 121 legislators and roughly 700 unique bills, there is not enough variability across our observations. Given that most of the variability in our data is in the activity features, we need to include them in our training. The issue this causes is that we can not predict on new incoming bills if the activity features are used for both training and predicting. Formally, this means our network has two requirements; we called these requirements our training requirement and our prediction requirement. The training requirement is that we need to use some of our activity features during the training process to add the necessary variability to our data. The prediction requirement is that we need to be able to predict using just the legislator and bill features so that we can predict on new incoming bills. From these requirements, we built Democracy2Vec to tackle our goal. This section describes the structure of our model in detail which can be seen in Figure 5.1. Our model has three unique layers: the single embedding layer, the multiple embedding layer, and the output layer. 


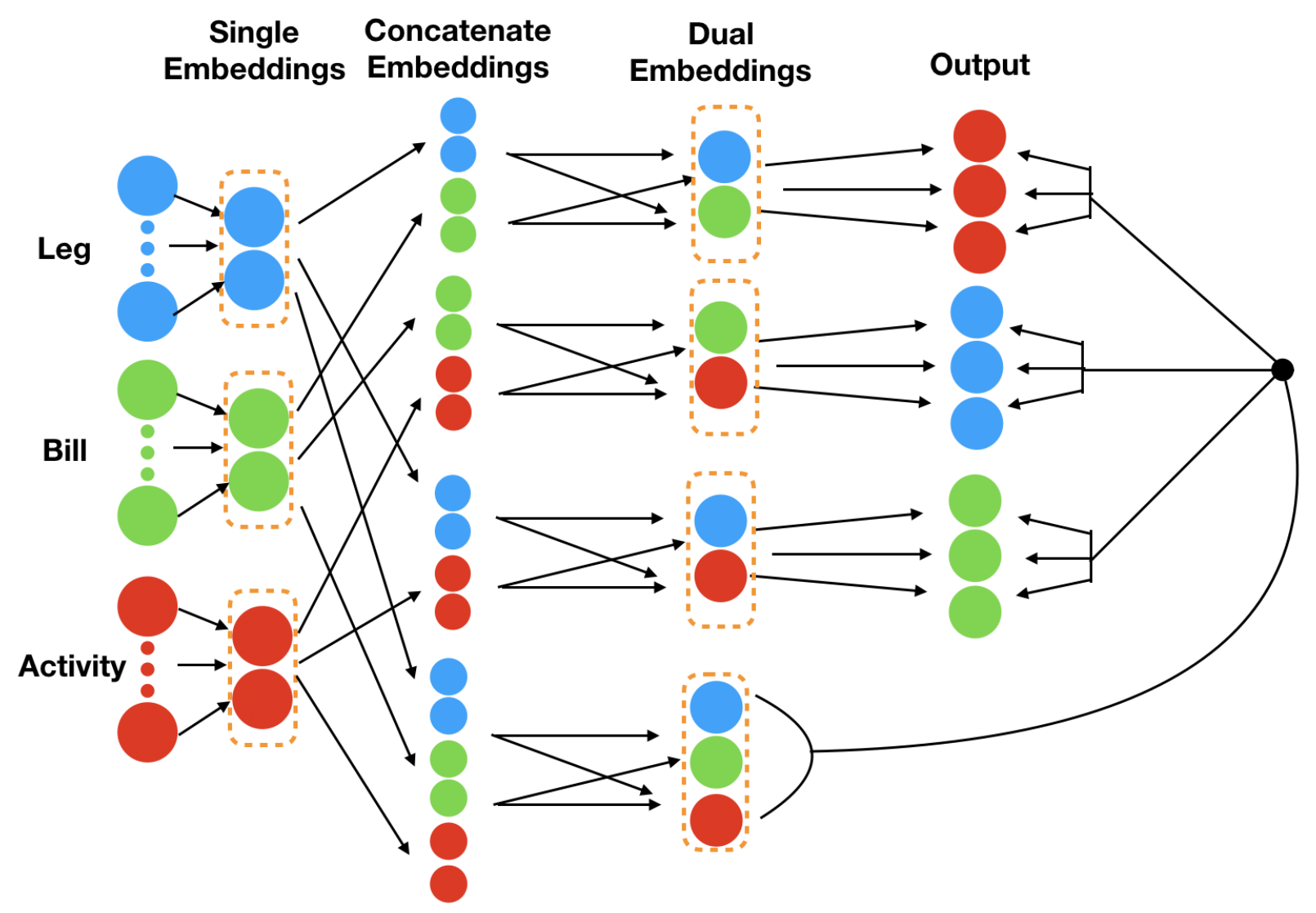

Figure 5.1: Democracy2Vec model, amount of neurons and weights not to scale.

\subsection{Single Embedding Section}

The first layer of our network creates a reduced embedding representations of each of our feature types: legislator, bill, and activity. Each data type embedding has fewer neurons than the original input feature set. For instance, we have roughly 60 bill features, while our bill single embedding section has 12 neurons. This single embedding allows us to learn important features and reduce the dimensionality of our feature space independent from other features. 


\subsection{Multiple Embedding Section}

Using the single embeddings from the previous section, we created four new vectors. Three of these vectors are dual embeddings, as they are created by concatenating two single embeddings: legislator/bill, bill/activity, and legislator/activity. The fourth vector is referred to as a global embedding, where all three single embeddings concatenated into one vector. We then create a reduced embedding representation of all four vectors of a chosen size, 10 neurons. By standardizing the size of the multiple embeddings, we have an equal number of neurons being used to calculate an output.

\subsection{Output Section}

Each of the dual embeddings are used to predict values related to the feature type they are missing. The legislator/bill dual embedding predicts activity features - specifically whether the legislator is a sponsor of the bill, if the legislator spoke on the bill, and if legislator had a non-zero sentiment score. This is a multi-label output and these values are predicted separate from each other. The bill/activity dual embedding helps predict which legislator performed the actions on the bill - this is a legislator feature. The legislator/activity dual embedding is used to predict a bill feature, the bill the legislator was acting on. Finally, the global embedding shares the same output neurons as the dual embedding but is used to predict all of the outputs. A list of these features can be seen in Table 5.2. 


\begin{tabular}{|l|l|l|}
\hline \hline Feature Type & Description & Output Type \\
\hline \hline Legislator & Which legislator performed the actions on the bill. & One-hot encoded \\
& vector \\
\hline Bill & The bill the legislator was acting on. & One-hot encoded \\
Activity & Is the legislator a sponsor of the bill. \\
\hline Activity & Did the legislator speak on the bill. & Binary \\
\hline Activity & $\begin{array}{l}\text { Did the legislator have a non-zero sentiment speak- } \\
\text { ing score. }\end{array}$ & Binary \\
\hline
\end{tabular}

Table 5.2: Output Features

\subsection{Explanation}

As stated above, we have two requirements. Our network needs to train with the activity features but predict without them. Our single embedding section, in combination with the multiple embedding section, solve both of these requirements. Each one of our dual embeddings and our global embedding essentially act as their own network, taking in two single embeddings. For example, one dual embedding takes in the legislator single embedding and the bill single embedding while another takes in the bill single embedding and the activity single embedding. It is important to note that the dual embeddings share the same single embeddings as inputs. So, in this example, the bill single embedding is the same for both of the dual embeddings. Since the dual embeddings use the same single embeddings, information that is learned during training from one dual embedding is then back propagated into the single embedding and used in the next epoch for other dual embeddings. This meets our training requirement because we use our activity features to train our network and 
learn about legislator activity patterns. Because the single embeddings are created independently and dual embeddings are created independently, we can isolate portions of the network because there are no interconnecting weights. This means that we can use the portion that creates the legislator single embedding, the bill single embedding and the legislator/bill dual embedding then predicts the activity features solving our prediction requirement. 


\section{Chapter 6}

\section{EXPERIMENTS}

The goal of our experiment is to produce meaningful embeddings that allows us to measure a legislator's passion on a given bill or all bills over an entire session. Note that we are not focused on our prediction accuracy, but rather trying to optimize our network for the legislator/bill dual embedding. We chose this embedding because it predicts three values that represent a legislator's activity: whether the legislator is a sponsor, whether the legislator spoke, and whether the legislator had a non-zero sentiment score on the bill.

\subsection{Training}

We split our data into two groups, a training and test set, with $80 \%$ of our data in the training set and $20 \%$ of our data in the test set. To calculate loss, we used the cross entropy loss function because all of our outputs were classifications. Since we wanted to optimize our network for the legislator/bill dual embedding, we weighed the loss of the activity prediction more. Additionally, the global embeddings contain information about the output, so we weighted the loss from the prediction by global embeddings less. A list of weights is provided in Table 6.1. 


\begin{tabular}{|l|l|l|}
\hline \hline Embedding Type & Prediction Data Type & Loss Weight \\
\hline \hline Dual & Legislator & 0.3 \\
\hline Dual & Bill & 0.2 \\
\hline Dual & Activity & 0.2 \\
\hline Global & Legislator & 0.125 \\
\hline Global & Bill & 0.125 \\
\hline Global & Activity & 0.05 \\
\hline
\end{tabular}

Table 6.1: Loss Weight used in Training.

After training our network for 300 epochs, we found that our network was only able to predict if legislator was sponsor well. In Tables 6.2 and 6.3 , we can see the precision, recall and f-score for our training and test set.

\begin{tabular}{|c|c|c|}
\hline \hline Prediction & Measurement & Score \\
\hline \hline Sponsor & Precision & .791 \\
\hline Sponsor & Recall & 0.723 \\
\hline Sponsor & F-score & 0.756 \\
\hline Not a Sponsor & Precision & 0.978 \\
\hline Not a Sponsor & Recall & 0.985 \\
\hline Not a Sponsor & F-score & 0.981 \\
\hline
\end{tabular}

Table 6.2: Sponsorship precision, recall, and F-score on our training data set.

\begin{tabular}{|c|c|c|}
\hline \hline Prediction & Measurement & Score \\
\hline \hline Sponsor & Precision & .789 \\
\hline Sponsor & Recall & 0.695 \\
\hline Sponsor & F-score & 0.739 \\
\hline Not a Sponsor & Precision & 0.977 \\
\hline Not a Sponsor & Recall & 0.986 \\
\hline Not a Sponsor & F-score & 0.982 \\
\hline
\end{tabular}

Table 6.3: Sponsorship precision, recall, and F-score on our test data set.

\subsection{Embeddings}

Once our model was sufficiently trained, we predicted on our entire data set and extracted our legislator/bill embeddings. These embeddings were continuous vectors 


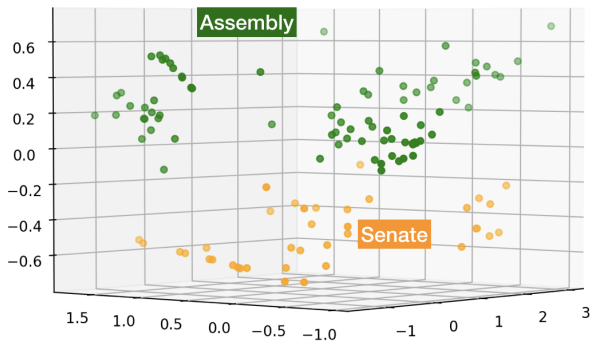

Figure 6.1: Average embeddings colored by house.

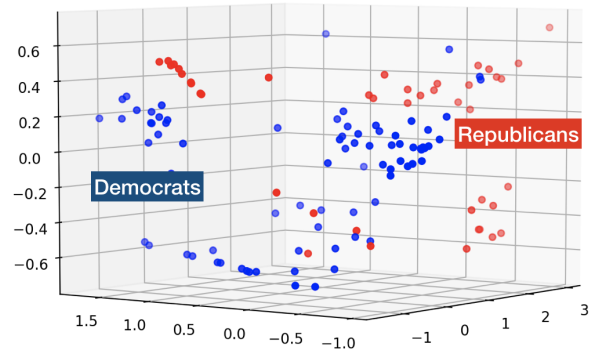

Figure 6.2: Average embeddings colored by party.

of length 10. To visualize and better understand these vectors, we performed PCA. Using the first three principal components, we were able to explain $98 \%$ of the variance of our data set. We then averaged the vectors over all bills with these principal component vectors and were able to notice some groupings.

In Figures 6.1 and 6.2 we observed that legislators of similar houses and party are grouped together. Because of this, we took our average embeddings and performed K-Means Clustering on them. Following these observations, we took our average embeddings, performed K-Means Clustering on them, and obtained eight distinct groups of legislators.

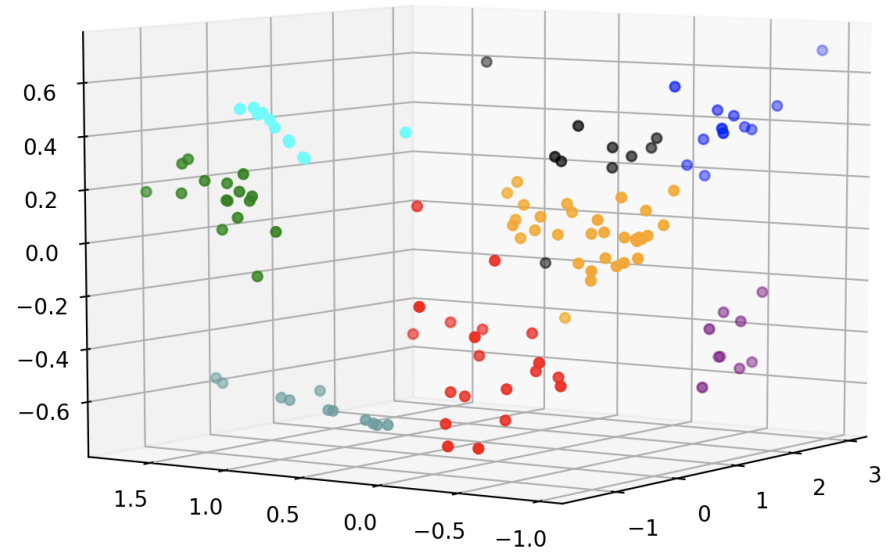

Figure 6.3: Embeddings averaged over all bills, colored by K-Means clusters. 


\section{Chapter 7}

CASE STUDY

\subsection{Validation Method}

To further investigate the clusters and the relationships within them, we performed a case study. We took our eight clusters to a political expert, Hans Poschman[5], to investigate our results. Mr. Poschman is the program and fellowship director of the Institute of Advanced Technology and Public Policy. He was also a district director for Assemblyman and Senator Sam Blakeslee and has spent his life in California politics. We provided Mr. Poschman with a list of legislators along with basic information such as their party, chamber, and cluster. We asked him to investigate the cluster and determine whether or not the cluster had any significance. Note, the number of the cluster was assigned during K-Means clustering and does not carry any meaning.

\subsubsection{Important Senate Democrats Cluster (Cluster 5)}

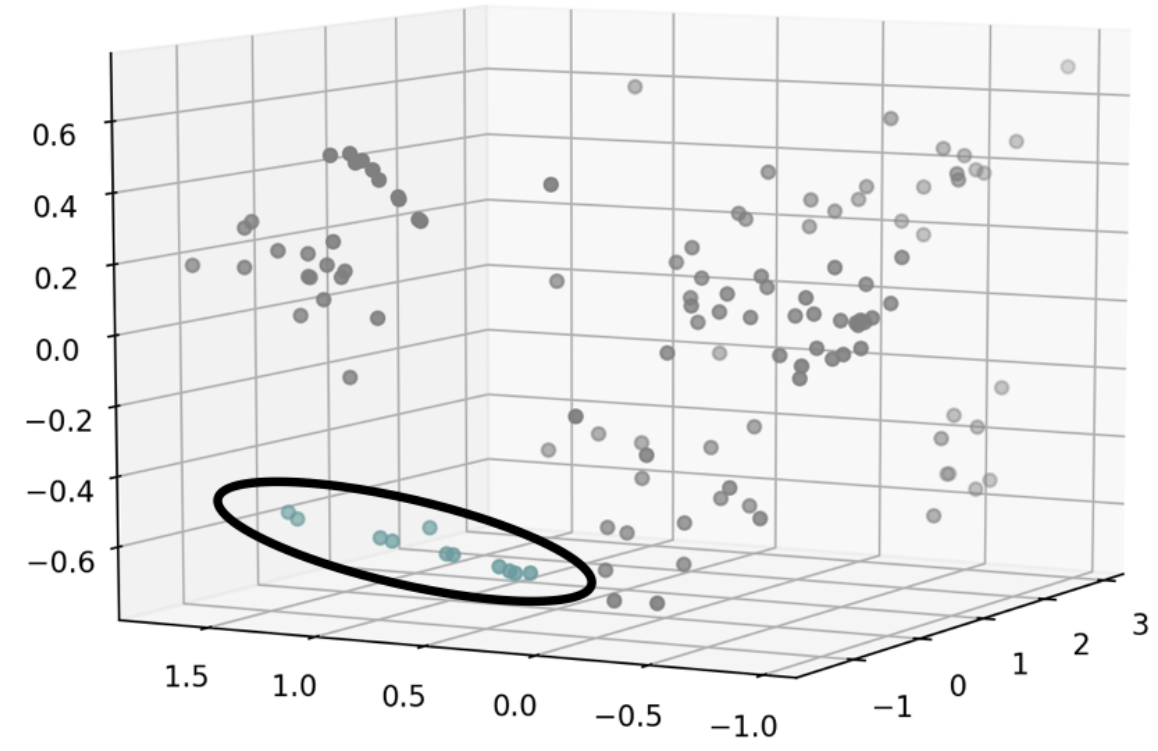

Figure 7.1: Important Senate Democrats Cluster 
One of the first clusters our political expert identified was cluster 5. This cluster is comprised of prominent Senate Democrats who were generally chairs of committees. For example, Lois Wolk, the majority whip in the Senate, was part of this group.

\begin{tabular}{|l|r|l|l|}
\hline Name & District & Chamber & party \\
\hline Fran Pavley & 27 & Senate & Democrat \\
\hline Loni Hancock & 9 & Senate & Democrat \\
\hline Richard Pan & 6 & Senate & Democrat \\
\hline Bill Monning & 17 & Senate & Democrat \\
\hline Lois Wolk & 3 & Senate & Democrat \\
\hline Marty Block & 39 & Senate & Democrat \\
\hline Jim Beall & 15 & Senate & Democrat \\
\hline Mark Leno & 11 & Senate & Democrat \\
\hline Holly Mitchell & 30 & Senate & Democrat \\
\hline Benjamin Allen & 26 & Senate & Democrat \\
\hline Ricardo Lara & 33 & Senate & Democrat \\
\hline
\end{tabular}

Table 7.1: Cluster 5 legislators. 


\subsubsection{Important Senate Republicans Cluster (Cluster 4)}

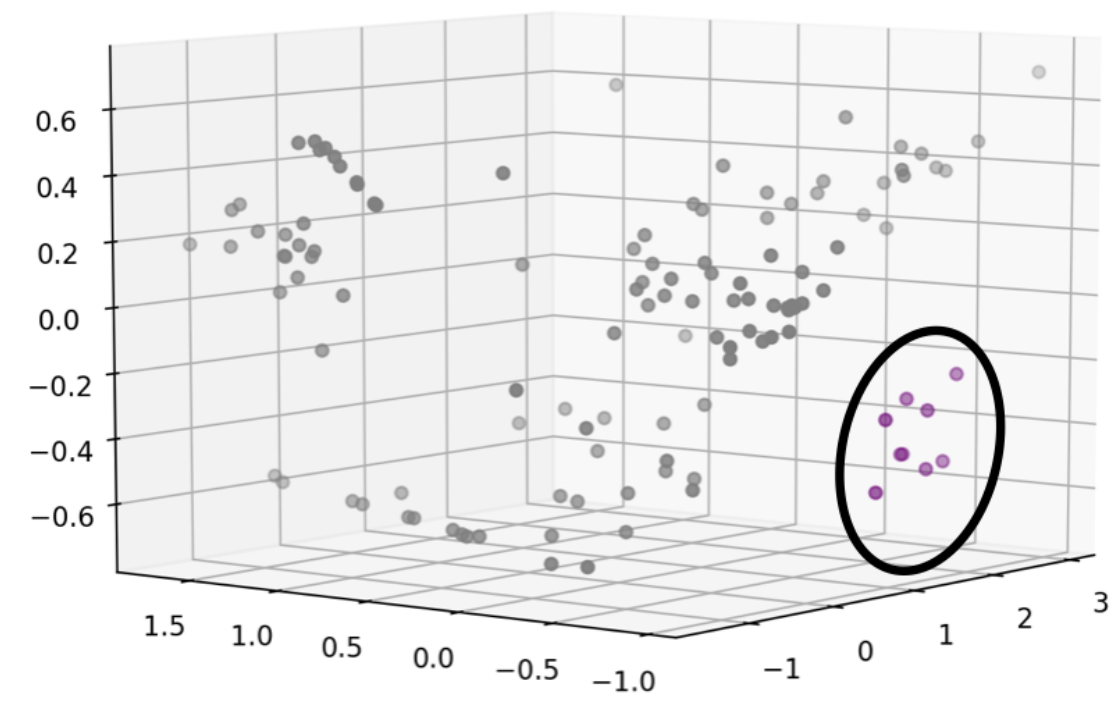

Figure 7.2: Important Senate Republicans Cluster

The second cluster Mr. Poschman identified was cluster 4. This cluster is similar to cluster 5, but for the Senate Republicans. It contains senior Republicans that were vice-chairs and also all of the minority leaders during the session, such as Jean Fuller.

\begin{tabular}{|l|r|l|l|}
\hline Name & District & Chamber & party \\
\hline Bob Huff & 29 & Senate & Republican \\
\hline Jean Fuller & 16 & Senate & Republican \\
\hline Patricia Bates & 36 & Senate & Republican \\
\hline Mike Morrell & 23 & Senate & Republican \\
\hline Sharon Runner & 21 & Senate & Republican \\
\hline Ted Gaines & 1 & Senate & Republican \\
\hline Anthony Cannella & 12 & Senate & Republican \\
\hline Tom Berryhill & 8 & Senate & Republican \\
\hline Andy Vidak & 14 & Senate & Republican \\
\hline
\end{tabular}

Table 7.2: Cluster 4 legislators. 


\subsubsection{Centered Senators Cluster (Cluster 0)}

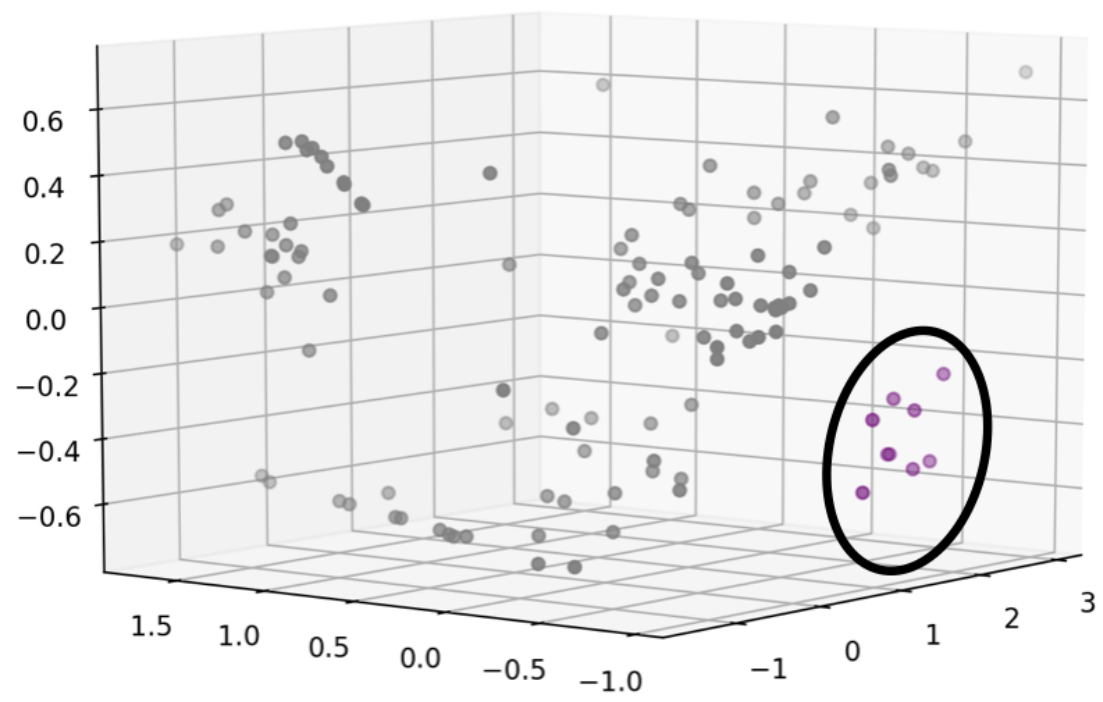

Figure 7.3: Centered Senators Cluster

In cluster 0, we found that a majority of the legislators were Senators. Interestingly, Mr. Poschman identified that this group mainly contained moderate Republicans and Conservative democrats. He also noted that these democrats were considered to be more pro-business rather than pro-union.

\begin{tabular}{|l|r|l|l|}
\hline Name & District & Chamber & party \\
\hline Isadore Hall & 35 & Senate & Democrat \\
\hline Jeff Stone & 28 & Senate & Republican \\
\hline Ben Hueso & 40 & Senate & Democrat \\
\hline Tony Mendoza & 32 & Senate & Democrat \\
\hline Joel Anderson & 38 & Senate & Republican \\
\hline Steve Glazer & 7 & Senate & Democrat \\
\hline Carol Liu & 25 & Senate & Democrat \\
\hline Janet Nguyen & 34 & Senate & Republican \\
\hline Jerry Hill & 13 & Senate & Democrat \\
\hline
\end{tabular}




\begin{tabular}{|l|r|l|l|}
\hline Jim Nielsen & 4 & Senate & Republican \\
\hline Mike McGuire & 2 & Senate & Democrat \\
\hline Susan Eggman & 13 & Assembly & Democrat \\
\hline Robert Hertzberg & 18 & Senate & Democrat \\
\hline Hannah-Beth Jackson & 19 & Senate & Democrat \\
\hline Kevin De Leon & 24 & Senate & Democrat \\
\hline Ed Hernandez & 22 & Senate & Democrat \\
\hline Richard Roth & 31 & Senate & Democrat \\
\hline John Moorlach & 37 & Senate & Republican \\
\hline Cathleen Galgiani & 5 & Senate & Democrat \\
\hline Rudy Salas & 32 & Assembly & Democrat \\
\hline
\end{tabular}

Table 7.3: Cluster 0 legislators.

\subsubsection{Centered Assemblymen Cluster (Cluster 1)}

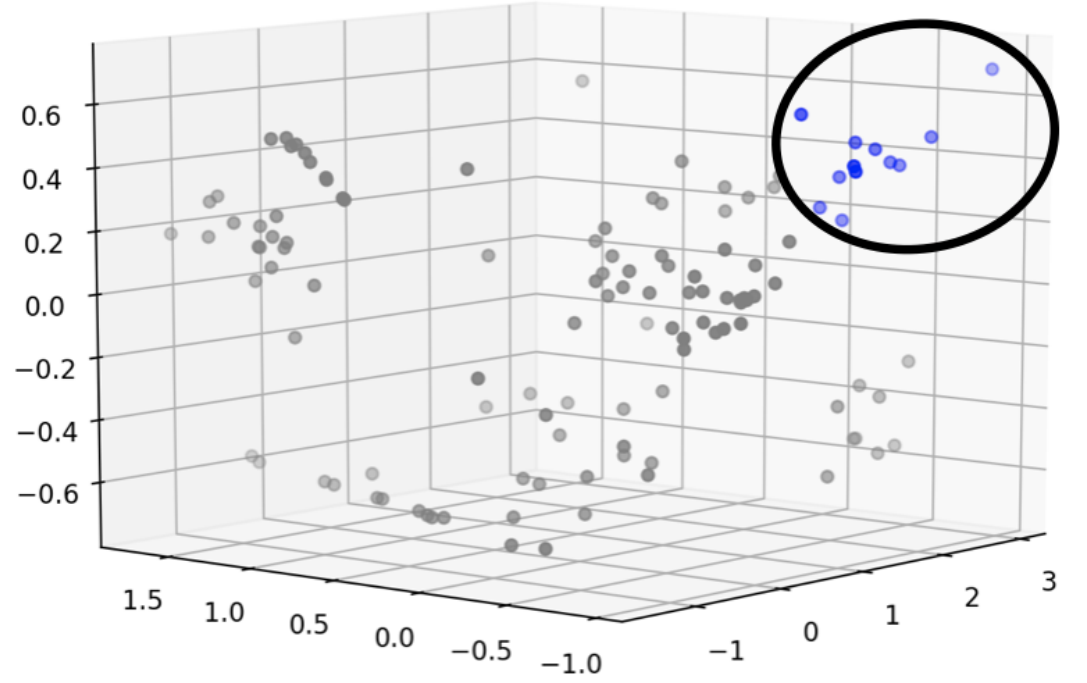

Figure 7.4: Centered Assemblymen Cluster

Cluster 1 was similar to cluster 0 as it also contained moderate Republicans and 
conservative Democrats, however cluster 1 contains Assemblymen instead of Senators. An example of this would be Katcho Achadjian.

\begin{tabular}{|l|r|l|l|}
\hline Name & District & Chamber & party \\
\hline Chad Mayes & 42 & Assembly & Republican \\
\hline Marc Steinorth & 40 & Assembly & Republican \\
\hline Beth Gaines & 6 & Assembly & Republican \\
\hline William Brough & 73 & Assembly & Republican \\
\hline Anthony Rendon & 63 & Assembly & Democrat \\
\hline Ken Cooley & 8 & Assembly & Democrat \\
\hline Brian Jones & 71 & Assembly & Republican \\
\hline David Hadley & 66 & Assembly & Republican \\
\hline Joaquin Arambula & 31 & Assembly & Democrat \\
\hline Ling Ling Chang & 55 & Assembly & Republican \\
\hline Kristin Olsen & 12 & Assembly & Republican \\
\hline K.H. "Katcho" Achadjian & 35 & Assembly & Republican \\
\hline
\end{tabular}

Table 7.4: Cluster 1 legislators. 


\subsubsection{Education-Focused Cluster (Cluster 3)}

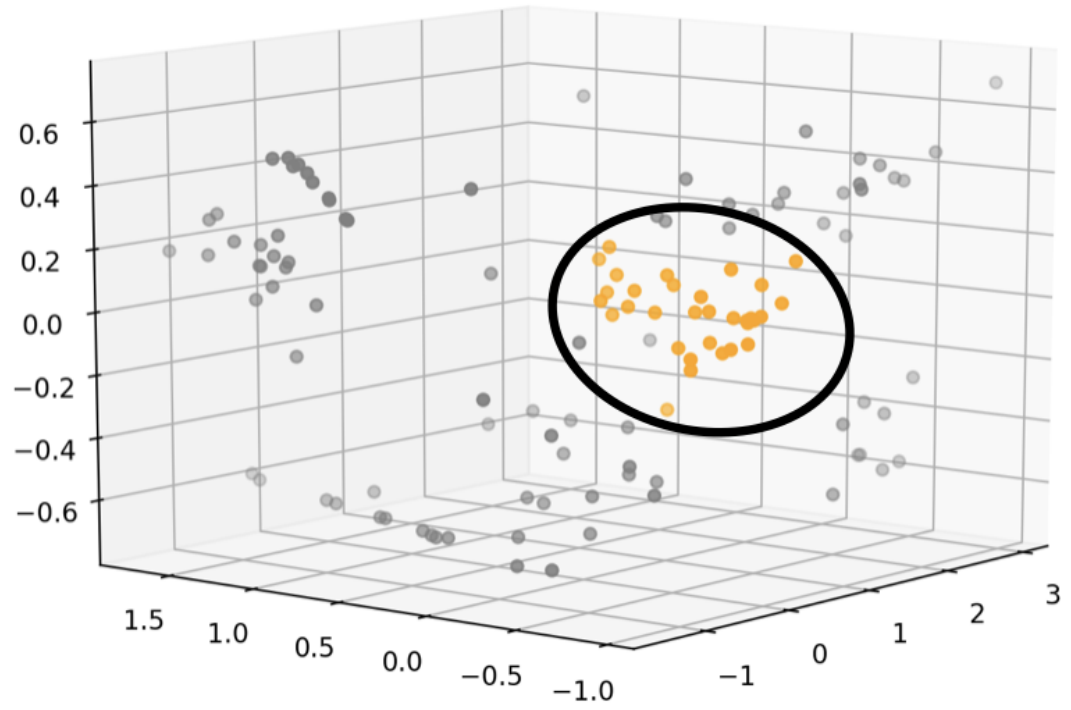

Figure 7.5: Education-Focused Cluster

The most difficult cluster to identify a common theme for was cluster 3. However, Mr. Poschman noticed that these legislators were heavily focused on legislation related to education. Funnily enough, we found that most legislators that resigned during the session were in this cluster as well.

\begin{tabular}{|l|r|l|l|}
\hline Name & District & Chamber & party \\
\hline Henry Perea & 31 & Assembly & Democrat \\
\hline Shirley Weber & 79 & Assembly & Democrat \\
\hline Mike Gipson & 64 & Assembly & Democrat \\
\hline Bill Quirk & 20 & Assembly & Democrat \\
\hline Bill Dodd & 4 & Assembly & Democrat \\
\hline Jim Wood & 2 & Assembly & Democrat \\
\hline Sebastian Ridley-Thomas & 54 & Assembly & Democrat \\
\hline Cristina Garcia & 58 & Assembly & Democrat \\
\hline Tom Daly & 69 & Assembly & Democrat \\
\hline
\end{tabular}




\begin{tabular}{|l|r|l|l|}
\hline Roger Hernandez & 48 & Assembly & Democrat \\
\hline Ed Chau & 49 & Assembly & Democrat \\
\hline Adam Gray & 21 & Assembly & Democrat \\
\hline Ian Calderon & 57 & Assembly & Democrat \\
\hline Jimmy Gomez & 51 & Assembly & Democrat \\
\hline Susan Bonilla & 14 & Assembly & Democrat \\
\hline Miguel Santiago & 53 & Assembly & Democrat \\
\hline Reginald Jones-Sawyer & 59 & Assembly & Democrat \\
\hline Toni Atkins & 78 & Assembly & Democrat \\
\hline Kansen Chu & 25 & Assembly & Democrat \\
\hline Mark Stone & 29 & Assembly & Democrat \\
\hline Patty Lopez & 39 & Assembly & Democrat \\
\hline Cheryl Brown & 47 & Assembly & Democrat \\
\hline Eduardo Garcia & 56 & Assembly & Democrat \\
\hline Mike Gatto & 43 & Assembly & Democrat \\
\hline Evan Low & 28 & Assembly & Democrat \\
\hline Bob Wieckowski & 10 & Senate & Democrat \\
\hline Luis Alejo & 30 & Assembly & Democrat \\
\hline Lorena Gonzalez Fletcher & 80 & Assembly & Democrat \\
\hline Marc Levine & 10 & Assembly & Democrat \\
\hline Matthew Dababneh & 45 & Assembly & Democrat \\
\hline Jose Medina & 61 & Assembly & Democrat \\
\hline Jim Frazier & 11 & Assembly & Democrat \\
\hline
\end{tabular}

Table 7.5: Cluster 3 legislators. 


\subsubsection{Democratic Line Breakers Cluster (Cluster 2)}

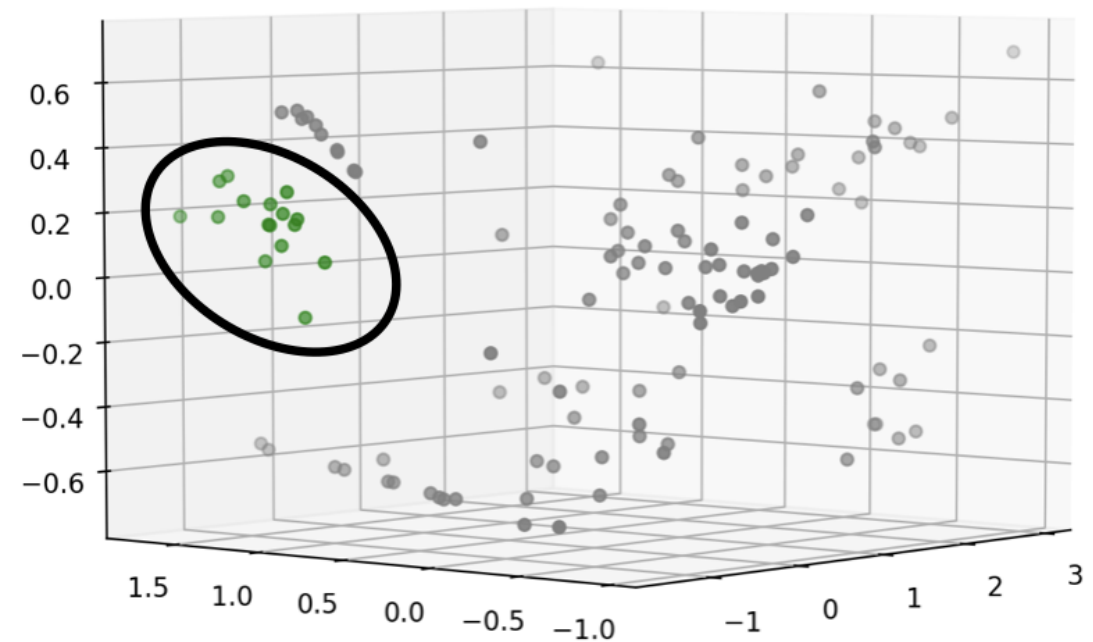

Figure 7.6: Democratic Line Breakers

Poschmann found that the legislators in cluster 2 were known to break party lines. $\mathrm{n}$ other words, these legislators were bipartisan and willing to change their vote to make progress. An example of this kind of legislator would be Jim Cooper.

\begin{tabular}{|l|r|l|l|}
\hline Name & District & Chamber & party \\
\hline Kevin Mullin & 22 & Assembly & Democrat \\
\hline Jacqui Irwin & 44 & Assembly & Democrat \\
\hline Freddie Rodriguez & 52 & Assembly & Democrat \\
\hline Philip Ting & 19 & Assembly & Democrat \\
\hline Chris Holden & 41 & Assembly & Democrat \\
\hline Rob Bonta & 18 & Assembly & Democrat \\
\hline Das Williams & 37 & Assembly & Democrat \\
\hline David Chiu & 17 & Assembly & Democrat \\
\hline Tony Thurmond & 15 & Assembly & Democrat \\
\hline Patrick O'Donnell & 70 & Assembly & Democrat \\
\hline
\end{tabular}




\begin{tabular}{|l|r|l|l|}
\hline Richard Gordon & 24 & Assembly & Democrat \\
\hline Richard Bloom & 50 & Assembly & Democrat \\
\hline Jim Cooper & 9 & Assembly & Democrat \\
\hline Kevin McCarty & 7 & Assembly & Democrat \\
\hline Nora Campos & 27 & Assembly & Democrat \\
\hline Adrin Nazarian & 46 & Assembly & Democrat \\
\hline
\end{tabular}

Table 7.6: Cluster 2 legislators.

\subsubsection{Republicans Line Breaker Cluster (Cluster 7)}

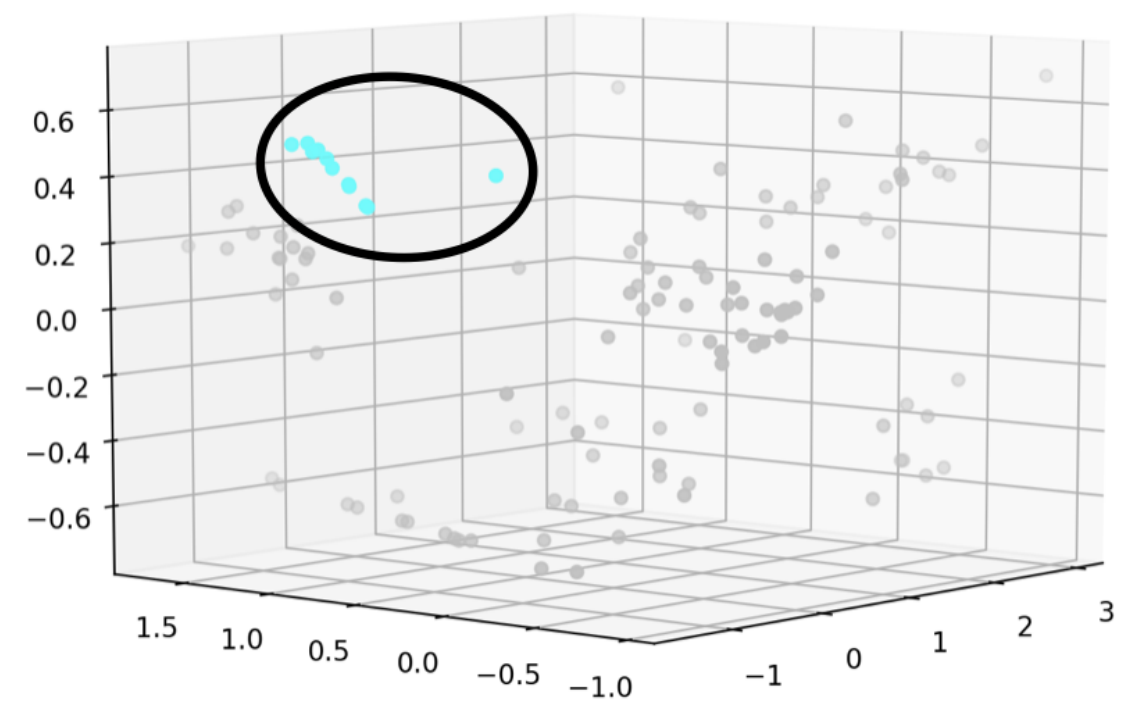

Figure 7.7: Republicans Line Breaker Cluster

Cluster 7 was similar to cluster 2, however these legislators were Republicans. Additionally, Pocshmann furthered noted that these legislators are outgoing and outspoken. Breaking party lines involves reaching out to Democratic legislators and negotiating with them. For example, Republican Assemblywoman Shannon Grove is in this cluster. 


\begin{tabular}{|l|r|l|l|}
\hline Name & District & Chamber & party \\
\hline Scott Wilk & 38 & Assembly & Republican \\
\hline Travis Allen & 72 & Assembly & Republican \\
\hline Jim Patterson & 23 & Assembly & Republican \\
\hline Frank Bigelow & 5 & Assembly & Republican \\
\hline Shannon Grove & 34 & Assembly & Republican \\
\hline Matthew Harper & 74 & Assembly & Republican \\
\hline Young Kim & 65 & Assembly & Republican \\
\hline Rocky Chavez & 76 & Assembly & Republican \\
\hline Jay Obernolte & 33 & Assembly & Republican \\
\hline Tom Lackey & 36 & Assembly & Republican \\
\hline Melissa Melendez & 67 & Assembly & Republican \\
\hline
\end{tabular}

Table 7.7: Cluster 7 legislators.

\subsubsection{Partisan Legislator Cluster (Cluster 6)}

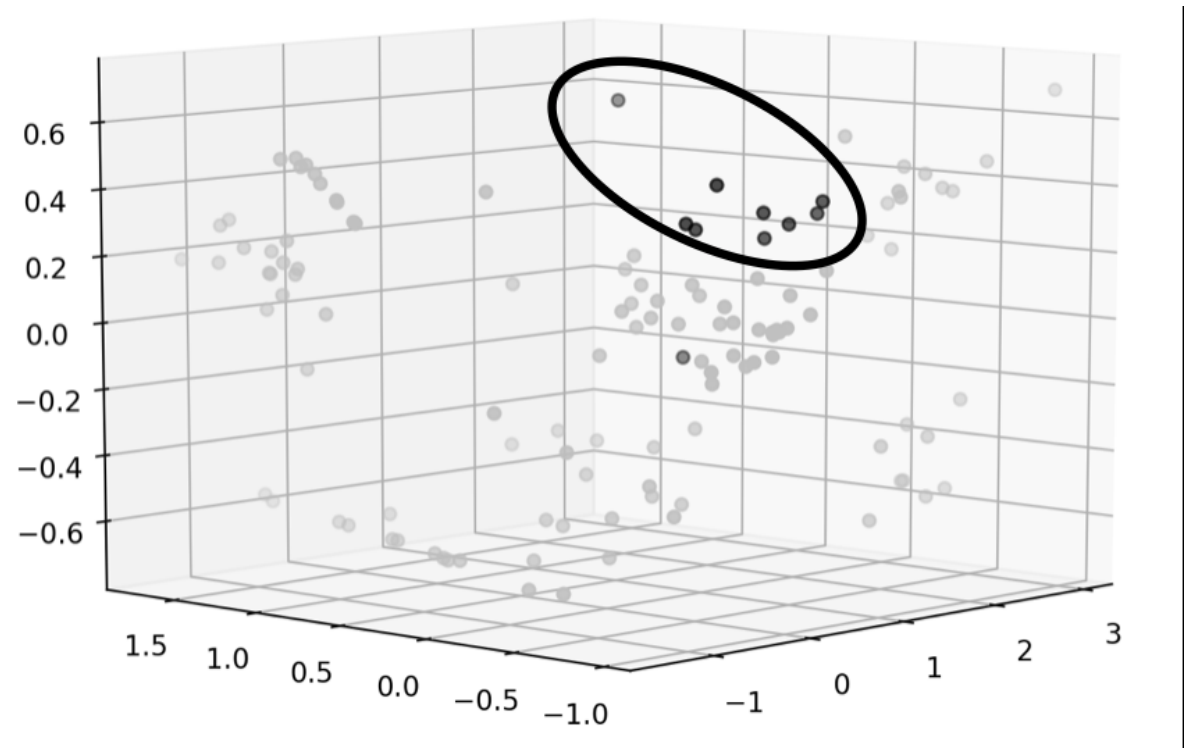

Figure 7.8: Partisan Legislators Cluster 
Finally, Mr. Poschman labelled cluster 6 as mainly partisan legislators. In other words, these legislators rarely worked with legislators from the opposing party. For example, Republican Assemblyman Brian Dahle represents district 1, which is heavily Republican. Legislators like Dahle satisfy the majority of his votes by not wavering from his party's base.

\begin{tabular}{|l|r|l|l|}
\hline Name & District & Chamber & party \\
\hline James Gallagher & 3 & Assembly & Republican \\
\hline Autumn Burke & 62 & Assembly & Democrat \\
\hline Marie Waldron & 75 & Assembly & Republican \\
\hline Eric Linder & 60 & Assembly & Republican \\
\hline Connie Leyva & 20 & Senate & Democrat \\
\hline Donald Wagner & 68 & Assembly & Republican \\
\hline Brian Dahle & 1 & Assembly & Republican \\
\hline Brian Maienschein & 77 & Assembly & Republican \\
\hline Catharine Baker & 16 & Assembly & Republican \\
\hline Devon Mathis & 26 & Assembly & Republican \\
\hline
\end{tabular}

Table 7.8: Cluster 7 legislators.

\subsubsection{Misclassifications}

While we were able to identify common themes among a majority of the legislators, we acknowledge that the clusters are not perfect. For example, we grouped Anthony Rendon into a cluster of moderate conservatives when he should be part of the partisan cluster 6. Another example of this would be Catherine Baker. While we grouped her into cluster 6, she should be in cluster 1 with our other centered Assemblymen. We attribute these mistakes to the K-Means Clustering algorithm. While investigating these misclassifications, we noticed that the legislator's 3-D point was always 
extremely close to the correct cluster (i.e. Anthony Rendon's 3-D point was very close to cluster 6 and Catherine Baker's point was close to cluster 1). 
Chapter 8

CONCLUSION AND FUTURE WORK

This thesis has provided three important contributions. First, we built a rich dataset describing legislator's activities on bills called the LAB dataset. This dataset was extracted from the Digital Democracy Project's database, transformed using a Python pipeline, and segmented into three feature types: legislator features, bill features, and activity features. With over 1200 features, this dataset can be used in other research and analyses. For example, researchers could use this dataset for building a vote prediction model or analyzing how influential legislators over bill life cycles. Furthermore, this experiment was run using data from the 2015-2016 California State Legislature. We chose this session because California had the most complete feature set across all four state in Digital Democracy's database. Unfortunately, we were unable to re-run out experiment on different states because of the unique differences in the data between states. Our data pipeline could be modified to collect data on other states. Finally, one of the goals of Digital Democracy Research Platform is to provide API's for public access to their data. As future work, an API could be created for the project to access the LAB dataset and the embeddings we created.

Second, we produced meaningful embeddings from our novel neural network architecture called Democracy2Vec. This neural architecture allowed us to train our model with a full set of features but predict with a subset of those features. We trained this network to predict whether or not a legislator was a sponsor, if they spoke on a bill, and if their sentiment towards the bill was not neutral. During training, we used the legislator, bill, and activity features from our LAB dataset then we predicted on our entire data set just using legislator and bill features. From this network, we extracted embeddings that uniquely describe a legislator and how they are likely to act on a bill. In general, embeddings are extremely valuable and can be 
applied to a variety of use cases [29][21][32]. Some future work with these embeddings can include using them as input to a vote prediction model. Additionally, researcher can investigate the other embeddings created from predictions using legislator and activity features and bill and activity features. An example of future work for these embeddings can be using the embeddings as input into a model that predicts if a bill will pass or if the bill needs to be revised. Another direction for future work could be investigating sponsorship prediction. Our network also predicted sponsorship quite well considering the size and sparse nature of our dataset. This could be beneficial when writing or editing a bill to see predict which legislators would support it. Finally, given that this is a novel network, future work should also test this network with a more balanced data set and in different domains. An example of an applicable domain could be in the medical field. Our model could potentially be trained using three medical measurements as input and the output for our dual embeddings could be the missing measurement. If successful, given two medical measurements, our model could predict the third.

Our third contribution is the case study we ran to explain and verify the meaning of our embeddings. This case study showed that our embeddings explained how legislators were likely going to act on a bill over a session. With these embeddings, we saw clusters of house, party, and political interest.

Overall, we believe that these contributions can be a stepping stone for political research. All of the code and data files for our LAB dataset, data pipeline, Democracy2Vec, and our embeddings have been given to the Digital Democracy Project and they will be publicly available on their Github repo [30]. We hope to see researchers use these contributions as powerful and effective inputs for their work. 


\section{BIBLIOGRAPHY}

[1] Cal Poly Github. http://www.github.com/CalPoly.

[2] California Bill Process. https://www.calstate.edu/acadsen/Records/ Agenda/documents/The_California_Legislative_Process.pdf.

[3] Digital Democracy. https://www.digitaldemocracy.org.

[4] FollowTheMoney. https://www.followthemoney.org.

[5] Hans Poschman resume. https://docs.google.com/document/d/ 1N JND2qIC1qWXYubu9rAZdsvHzK5WHydmk-F04hcKV1Y/edit?ts=5c0d3007.

[6] How To Improve Statehouse Reporting. https://hewlett.org/how-to-improve-statehouse-reporting.

[7] In 2019, All But One State Legislatures Is Controlled by One Party. http://www.governing.com/topics/politics/gov-state-politicsgovernors-2019.html.

[8] Is Statehouse News Actually Declining, or Just Different? http://www .governing. com/columns/assessments/gov-statehousereporting-news-coverage.html.

[9] LegInfo. https://leginfo.legislature.ca.gov.

[10] MapLight. https://maplight.org.

[11] OpenStates. https://openstates.org.

[12] Overview of Legislative Process. http://www.leginfo.ca.gov/bil2lawx.html. 
[13] pandas. https://pandas.pydata.org.

[14] PCA Explanation.

https://stats.stackexchange.com/questions/2691/making-sense-ofprincipal-component-analysis-eigenvectors-eigenvalues.

[15] The precipitous decline of state political coverage. https : //www . washingtonpost . com/blogs/govbeat/wp/2014/07/10/theprecipitous-decline-of-state-politicalcoverage/?noredirect=on\&utm_term=. ea13866ab2b5.

[16] Textblob: Simplified text processing. https://textblob.readthedocs.io/en/dev/\#.

[17] Vader sentiment. https://github.com/cjhutto/vaderSentiment.

[18] H. Abdi and L. J. Williams. Principal component analysis. WIREs Comput. Stat., 2(4):433-459, July 2010.

[19] A. Budhwar. Predicting the vote using legislative speech. Master's thesis, California Polytechnic State University, San Luis Obispo, California, USA, 2018.

[20] N. A. de Guia, J. E. Cohen, M. J. Ashley, R. Ferrence, J. Rehm, D. T. Studlar, and D. Northrup. Dimensions underlying legislator support for tobacco control policies. Tobacco Control, 12(2):133-139, 2003.

[21] J. Devlin, M. Chang, K. Lee, and K. Toutanova. BERT: pre-training of deep bidirectional transformers for language understanding. CoRR, abs/1810.04805, 2018.

[22] A. Grover and J. Leskovec. Node2vec: Scalable feature learning for networks. In Proceedings of the 22Nd ACM SIGKDD International Conference on 
Knowledge Discovery and Data Mining, KDD '16, pages 855-864, New York, NY, USA, 2016. ACM.

[23] M. Iyyer, P. Enns, J. L. Boyd-Graber, and P. Resnik. Political ideology detection using recursive neural networks. In $A C L, 2014$.

[24] D. Kauffman. Learning alignments from legislative discourse. Master's thesis, California Polytechnic State University, San Luis Obispo, California, USA, 2017.

[25] A. Kornilova, D. Argyle, and V. Eidelman. Party matters: Enhancing legislative embeddings with author attributes for vote prediction. CoRR, abs/1805.08182, 2018.

[26] P. Kraft, H. Jain, and A. M. Rush. An embedding model for predicting roll-call votes. In Proceedings of the 2016 Conference on Empirical Methods in Natural Language Processing, EMNLP 2016, Austin, Texas, USA, November 1-4, 2016, pages 2066-2070, 2016.

[27] Q. V. Le and T. Mikolov. Distributed representations of sentences and documents. CoRR, abs/1405.4053, 2014.

[28] T. Mikolov, K. Chen, G. Corrado, and J. Dean. Efficient estimation of word representations in vector space. CoRR, abs/1301.3781, 2013.

[29] A. P. Parikh, O. Täckström, D. Das, and J. Uszkoreit. A decomposable attention model for natural language inference. CoRR, abs/1606.01933, 2016.

[30] D. D. Project. Digital democracy. https : //github.com/orgs/digitaldemocracy/teams/cal-poly-developers, 2013.

[31] Y. Shoji, K. Takahashi, M. J. Dürst, Y. Yamamoto, and H. Ohshima. 
Location2vec: Generating distributed representation of location by using geo-tagged microblog posts. In SocInfo, 2018.

[32] K. S. Tai, R. Socher, and C. D. Manning. Improved semantic representations from tree-structured long short-term memory networks. CoRR, abs/1503.00075, 2015.

[33] A. Wang. Tongs: Tldr; opinion network guide system. Master's thesis, California Polytechnic State University, San Luis Obispo, California, USA, 2017.

[34] C. Wu. Skewer: Sentiment knowledge extraction with entity recognition. Master's thesis, California Polytechnic State University, San Luis Obispo, California, USA, 2016. 